$D R-271$

ERDA/JPL/954374-76/2

\title{
SLICING OF SILICON INTO SHEET MATERIAL \\ Silicon Sheet Growth Development for the Large Area Silicon \\ Sheet Task of the Low Cost Silicon Solar Array Project \\ Second Quarterly Report, March 22, 1976-June 20, 1976
}

S. C. Holden

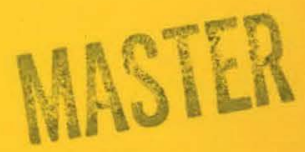

June 25, 1976

Work Performed Under JPL Contract No. 954374

Vacuum Division

Varian Associates

Lexington, Massachusetts

\section{ENERGY RESEARCH AND DEVELOPMENT ADMINISTRATION}

Division of Solar Energy 


\section{DISCLAIMER}

This report was prepared as an account of work sponsored by an agency of the United States Government. Neither the United States Government nor any agency Thereof, nor any of their employees, makes any warranty, express or implied, or assumes any legal liability or responsibility for the accuracy, completeness, or usefulness of any information, apparatus, product, or process disclosed, or represents that its use would not infringe privately owned rights. Reference herein to any specific commercial product, process, or service by trade name, trademark, manufacturer, or otherwise does not necessarily constitute or imply its endorsement, recommendation, or favoring by the United States Government or any agency thereof. The views and opinions of authors expressed herein do not necessarily state or reflect those of the United States Government or any agency thereof. 


\section{DISCLAIMER}

Portions of this document may be illegible in electronic image products. Images are produced from the best available original document. 


\title{
NOTICE
}

This report was prepared as an account of work sponsored by the United States Government. Neither the United States nor the United Slates Energy Research and Development Administration, nor any of their employees, nor any of their contractors, subcontractors, or their empluyees, makes any warranty, express or implied, or assumes any legal liability or responsibility for the accuracy, completeness or usefulness of any information, apparatus, product or process disclosed, or represents that its use would not infringe privately owned rights.

This report has been reproduced directly from the best available copy.

Available from the National Technical Information Service, U. S. Department of Commerce, Springfield, Virginia 22161

\author{
Price: Paper Copy $\$ 4.50$ (domestic) \\ $\$ 7.00$ (foreign) \\ Microfiche $\$ 2.25$ (domestic) \\ $\$ 3.75$ (foreign)
}




\title{
SLICING OF SILICON INTO SHEET MATERIAL
}

Silicon Sheet Growth Development for the Large Area Silicon Sheet Task of the Low Cost Silicon Solar Array Project

SECOND QUARTERLY REPORT

$$
\text { By }
$$

This Notice an account of work This repon wy the United States Government. Neither sponsored by the Unted States nor the United States Energy Research and Development Adminintration, nor any or their employees, nor any of their conkes any subcontractors. or their warranty, express or impled ore asucy, completeness tiability or respons in formation, apparatus, product or or userulness of any in represents that its use would no process discelo or

\author{
S. C. Holden \\ June 25,1976 \\ JPL Contract No. 954374 \\ Varian Associates \\ Lexington Vacuum Division \\ 121 Hartwe 11 Avenue \\ Lexington, Massachusetts. 02173
}

This work was performed for the Jet Propulsion Laboratory, California

Institute of Technology, under NASA Contract NAS7-100 for the U.S. Energy Research and Development Administration, Division of Solar

Energy.

The JPL Low-Cost Silicon Solar Array Project is funded by ERDA and forms part of the ERDA Photovoltaic Conversion Program to initiate a major effort toward the development of low-cost solar arrays. 


\section{THIS PAGE}

\section{WAS INTENTIONALLY \\ LEFT BLANK}


TABLE OF CONTENTS

1.0 Summary ................... 1

2.0 Introduction .......... 3

3.0 Experimental Results ......... 4

4.0 Technical Discussion ........ 15

4.1 Cutting Efficiency....... 15

4.2 Blade Wear . . . . . . . 16

4.3 Kerf Loss . . . . . . . . . 20

5.0 Characterization Data ....... . 26

6.0 Conclusions and Recommendations ..... . 26

7.0 Future Work . . . . . . . . . . . . 27

Appendix ............ 28

New Technology

Man-hours and Costs

Program Plan (Updated)

Multiblade Slicing of Hard Materials with Fixed Abrasive Blades 


\section{LIST OF FIGURES}

PAGE

Figure 1 Silicon Slurry Sawing Efficiency

Test \#1-061

Figure 2 Silicon Slurry Sawing Efficiency

Test \#1-062

Figure 3 Silicon Slurry Sawing Efficiency

Test \#1-063

Figure 4 Efficiency vs. Cutting Pressure

Figure 5 Wear Ratio vs. Cutting Pressure

Figure 6 Kerf Loss, $x_{k}$, vs. Blade Thickness, $x_{b}$

Figure 7 Abrasive Kerf Loss, $x_{a}$, vs. Cutting Pressure

Figure 8 Abrasive Kerf Loss, $x_{a}$, vs. Mean Abrasive Particle Diameter, $d_{50 \%}$

Figure 9 Abrasive Kerf Loss, $X_{a}$, vs. Maximum Abrasive 25 Particle Diameter, $d_{\max }$

\section{LIST OF TABLES}

Table 1 Summary of Slurry Sawing - Parameter $7-11$ Study

Table 2 Average Particle Size of SiC Abrasive 23 


\subsection{SUMMARY}

Slicing tests of silicon to show the dependence of cutting rate on operating conditions are complete. Cutting rate is linear with cutting force per blade and bladehead speed, and inversely proportional to kerf width (loss) and kerf length. The dimensionless parameter of cutting efficiency, $\bar{\varepsilon}$, is a good measure of the performance of a multiblade slicing system. Low contact pressure between the blades and the silicon workpiece result in increased wafer accuracy and cutting efficiency. Blade. wear seems to be stable for all slicing tests, and is slightly lower with low cutting pressure.

There is a minimal difference in the slicing of 100 and 111 . oriented silicon ingots. As abrasive size was varied from \#600 SiC to \#1200 SiC, a reduction in cutting efficiency was experienced. \#800 SiC will be tried since it gave low kerf loss (blade thickness plus 0.0025 inch) and relatively high cutting efficiency $(0.78)$. Variations in slurry mix and oil type will be tried to produce acceptable cutting with fine abrasive slurries. Increasing abrasive density and lowering oil viscosity in the slurry improved cutting efficiency with finer abrasives.

Blade wear was characterized by volume of worn blade relative to volume of silicon abraded. Wear ratio, $r$, was typically from 0.06 to 0.07 for slicing with \#600 SiC abrasive. Wear with finer abrasives was higher.

A dynamometer is now being used to measure cutting force between the silicon workpiece and the blades. Silicon wafers of 0.013 inch thickness have been sliced.

0ther plans include ordering of thin blades of various. hardness, slicing of 4 inch diameter silicon into wafers less than 0.010 inch thick, completion of surface damage and profile characterization, testing of various slurry compositions for 
suspension and cutting capabilities, testing feedback control of cutting force and predicting cutting force limits based on wafer strength and blade stability.

A shift in Program Plan will allow determination of slurry. and abrasive effects on slicing as the next major goal. 


\subsection{INTRODUCTION}

The first series of multiblade wafering tests has been completed. The performance of slurry sawing was characterized by an abrasive wear mechanism, and the cutting rate was predicted to be linearly proportional to cutting force per blade and bladehead reciprocating speed, and inversely proportional to kerf length and kerf width. A scalar term including material hardness and cutting efficiency, together, can characterize the removal of silicon work material by the individual abrasive particles. The mechanism was assumed to be indentation of cutting points into the silicon and ploughing of a trough. It is very unlikely that this mechanism is exactly correct, since silicon would abrade in a brittle manner. However, for a relative measure of cutting performance, the model is adequate to judge and predict the performance of a slicing system.

The use of fine abrasives in slurry sawing gives three advantages. The kerf loss is small in proportion to the abrasive particle size, and material savings will be realized. Since the kerf loss is small, the amount of abrasion required to produce a slice is lower, and cutting rate can improve. Also, the finish and accuracy of wafers should improve as the degree of kerf loss due to abrasive is reduced. The finest abrasive that gives adequate cutting rate, low blade wear and good wafer accuracy will be sought to slice silicon into sheet material for solar cells. 


\subsection{EXPERIMENTAL RESULTS}

Table 1 is a complete summary of all wafering tests for the first portion of this effort. The tests have been designed to show trends in cutting rate and accuracy of silicon wafers as changes in the slicing parameters have been altered from standardized conditions. Standard conditions were: $25 \mathrm{~mm}$ work material kerf length, .008 inch thick blades of hardened 1095 steel 1/4 inch high, \#600 grit silicon carbide abrasive mixed at two pounds per galion of Process Research PC 0il, four ounces per blade of cutting force and bladehead speed of 1600 inch per minute.

Cutting efficiency was calculated from cutting rate history using the equation developed in the "First Quarterly Report".

$$
\frac{d z}{d t}=\frac{L \vec{\varepsilon}}{\pi p}\left(\frac{d \ell}{d t}\right) \frac{1}{y_{k} x_{k}}
$$

$\mathrm{dz} / \mathrm{dt}$ is the vertical cutting rate, $\mathrm{L}$ is the applied vertical load per.blade, $p$ is the work material hardness (assumed to be $1150 \mathrm{~kg} / \mathrm{mm}^{2}$ for silicon), $\mathrm{d} \ell / \mathrm{dt}$ is the reciprocating speed of the bladehead, $x_{k}$ and $y_{k}$ are the kerf length and width (blade contact area). The cutting efficiency, $\bar{\varepsilon}$, is a dimensionless measure of the cutting capability of a blade loaded with abrasive.

Test 1-001 was a first effort to show the condition of the wafering saw and to give a reference in slicing four inch diameter wafers. In Tests 1-011 through 1-015, load on a $25 \mathrm{~mm}$ kerf length block of silicon was varied from 2 to 10 ounces per blade. Cutting rate increased in each test, as expected, but the cutting efficiency dropped from 1.13. to .86. Test 1-015 was aborted when the work piece broke away from the submount under excessive horizontal load.

Associated with the loss of cutting efficiency as blade load increased was a reduction of wafer accuracy. Kerf loss was also greater with increasing cutting force. Blade wear ratio, $r$, was consistently in the range of .060 to .076 for these tests. See Section 4.2 for a discussion of blade wear ratio. 
In Tests 1-021 through 1-024, kerf length was increased from 0.494 inch to 4.19 inch. The cutting rate decreased as kerf length was lengthened, but the efficiency of cutting increased as the kerf length increased. Associated with improved efficiency was good wafer accuracy and low kerf loss.

In Tests 1-031 to 1-034, blade sizè alone was varied in the standard slicing test. Cutting efficiency for all tests was in the range of 0.91 to 1.04 . The highest efficiency was recorded for 0.004 thick blades, and it should be noted that cutting rate was already expected to be higher than 0.008 inch thick blades by $43 \%$ since the kerf loss was less. The 0.004 inch blades did produce less accurate wafers, most likely due to lower mechanical stability.

The machines reciprocating speed alone was changed from 480 to 1920 inches per minute in Test 1-041. In all speed ranges, cutting rate was proportional to speed as predicted in Equation 1. The overall efficiency was 0.90 , slightly lower than with comparable tests at fixed speed. The cutting rate exhibits slight inertia if the machine is stopped, or has a change in cutting conditions. The cutting rate rises after a transition to an equilibrium level. With the many stops and starts to change speed and measure blade wear, the overall cutting efficiency is understandably lower.

The ratio of abrasive to oil in the slurry was lowered to $1 / 2$ pound per gallon in Test 1-042. Cutting rate was lower than the comparable Test 1-012, but accuracy was nearly the same. A cutting test is underway to explore the effect of a higher density of slurry.

In Tests $1-051$ to $1-054,\langle 100\rangle$ silicon was sliced to point out differences in material. In other tests $\langle 111\rangle$ silicon was used. Cutting rate was generally lower than with $\langle 111\rangle$ silicon; but a sticking vertical feed in 1-052 and 1-053 gave excessively low cutting rate. 1-054 repeated Test 1-052 with a properly operating feed. Cutting rate was low by $10 \%$ and accuracy was slightly worse for $\langle 100\rangle$ wafers. The difference was slight, and the best assumption is that slightly different slurry conditions are required to make both materials saw identically. 
At a load of 3 ounces per blade, abrasive size was varied in Tests 1-061 to 1-063. \#1200, \#1000 and \#800 SiC was used to form a slurry with standard PC 017 . Figures 1, 2 and 3 show the reduction of cutting rate to cutting efficiency for the three tests.

The slurry mix in pounds of abrasive per gallon of oil was initially lower than had been used for \#600 SiC. It was reasoned that similitude of the cutting interface might be best achieved by providing an equivalent number of particles per square inch of oil film. With small diameter particles a lower weight of abrasive is required.

With \#1200 SiC in Test 1-061, the cutting rate was very low initially. By adding a 30 SUV rated mineral oil to the standard PC 011 (in 1:1 ratio), the rate picked up dramatically as shown in'Figure 1. By adding more abrasive to the slurry, the cutting rate increased even more. Kerf loss was only 0.0097 inches with the 0.008 blades, but efficiency was limited to 0.33 . \#1000 SiC gave a cutting efficiency of 0.51 (see Figure 2). When the oil was thinned as described above, a reduction of cutting efficiency to 0.37 occurred; presumably due to the reduced abrasive density in the slurry. Again, an increase in abrasive mix to 3 pounds per gallon resulted in an increase in efficiency to 0.52 . Kerf loss was low due to the size of abrasive particles, and wafer accuracy was good. Figure 3 shows the cutting results for \#800 SiC. With low slurry density, low efficiency resulted. Increasing the slurry density improved the cutting efficiency to 0.79 , with a further increase giving no change. Thinning of the oil was not tried. Kerf loss was only 0.0105 inch for the 0.008 inch blades, and accuracy was comparable to or better than cutting with \#600 SiC. The difference in cutting rate between $\# 600$ and \#800 abrasive, when the difference in kerf loss is considered, is minimal (0.0015 inch/ $\mathrm{min} / \mathrm{oz}$ force for $\# 800$ and 0.0018 to $0.0020 \mathrm{inch} / \mathrm{min} / \mathrm{oz}$ force for $\# 600$ ).

In Tests 1-053 and 1-054, 0.016 inch thick blade spacers were used, resulting in 0:013 inch thick wafers. There were no special handling problems encountered with this thickness. A dynamometer system has been installed and is used to monitor the vertical cutting force, I.t is capable to resolving cutting forces to within 0.1 pound. 
TABLE 1

SUMMARY OF SLURRY SAWING - PARAMETER STUDY

\begin{tabular}{|c|c|c|c|c|c|}
\hline PARAMETER & $1-001$ & $1-011$ & $1-012$ & $1-013$ & $1-014$ \\
\hline DATE & $3 / 4-10 / 76$ & $3 / 12-16 / 76$ & $3 / 17-18 / 76$ & $3 / 19 / 76$ & $3 / 22-23 / 76$ \\
\hline MATERIAL & $\operatorname{Si}\{111\}$ & $\operatorname{Si}\{111\}$ & Si $\{111\}$ & Si $\{111\}$ & $\operatorname{Si}\{111\}$ \\
\hline LOAD (oz/blade) & 4 & 2 & 4 & 6 & 8 \\
\hline SLIDING SPEED (in/min) & 1600 & 1600 & 1600 & 1600 & 1600 \\
\hline BLADE SIZE (inch) & $.008 \times 1 / 4$ & $.008 \times 1 / 4$ & $.008 \times 1 / 4$ & $.008 \times 1 / 4$ & $.008 \times 1 / 4$ \\
\hline SPACER (inch) & .025 & .025 & .025 & .025 & .025 \\
\hline KERF LENGTH & 3.88 & .984 & .984 & .984 & .984 \\
\hline ABRASIVE & $\# 600 \mathrm{SiC}$ & $\# 600 \mathrm{SiC}$ & $\# 600 \mathrm{SiC}$ & \#600 SiC & $\# 600 \mathrm{SiC}$ \\
\hline SLURRY MIX (1b/gal) & 2 & 2 & 2 & 2 & 2 \\
\hline SLURRY OIL & PC & $\mathrm{PC}$ & $P C$ & $\mathrm{PC}$ & $\mathrm{PC}$ \\
\hline EFFICIENCY (TYP) & 1.09 & 1.13 & 1.08 & .87 & .86 \\
\hline WEAR RATIO & .045 & .076 & .069 & .070 & .060 \\
\hline KERF WIDTH & .0107 & .0113 & .0120 & .0119 & .0132 \\
\hline PRESSURE $\left(\mathrm{oz} / \mathrm{in}^{2}\right)$ & 96 & 180 & 339 & 514 & 615 \\
\hline THICKNESS (AVE.) & .02226 & .02170 & .02102 & .02113 & .01978 \\
\hline STD. DEVIATION & .00080 & .00066 & .00177 & .00240 & .00334 \\
\hline TOTAL VARIATION (AVE) & .00127 & .00076 & .00229 & .00203 & .00335 \\
\hline STD. DEVTATION & .00065 & .00047 & .00149 & .00209 & .00195 \\
\hline STD. DEVIATION (AVE.) & .00057 & .00039 & .00120 & .00111 & .00178 \\
\hline STD DEVIATION & .00027 & .00025 & .00079 & .00118 & .00106 \\
\hline VARIATION (AVE.WAFER) & .00085 & .00041 & .00147 & .00113 & .00178 \\
\hline
\end{tabular}


TABLE 1

SUMMARY OF SLURRY SAWING - PARAMETER STUDY

\begin{tabular}{|c|c|c|c|c|c|}
\hline PARAMETER & $1-015$ & $1-021$ & $1-022$ & $1-023$ & $1-024$ \\
\hline DATE & $3 / 31 / 76$ & $4 / 26-27 / 76$ & $4 / 7-2 / 76$ & $4 / 5-8 / 76$ & $5 / 3-10 / 76$ \\
\hline MATERIAL & Si $\{111\}$ & Si $\{111\}$ & $\operatorname{Si}\{111\}$ & $\operatorname{Si}\{111\}$ & $\operatorname{Si}\{111\}$ \\
\hline LOAD (oz/blade) & 10 & 4 & 4 & 4 & 4 \\
\hline SLIDING SPEED (in/min) & 1600 & 1600 & 1600 & 1600 & 1600 \\
\hline BLADE SIZE (inch) & $.008 \times 1 / 4$ & $.008 \times 1 / 4$ & $.008 \times 1 / 4$ & $.008 \times 1 / 4$ & $.008 \times 1 / 4$ \\
\hline SPACER (inch) & .025 & .025 & .025 & .025 & .025 \\
\hline KERF LENGTH & .984 & .492 & 1.968 & 2.710 & 4.19 \\
\hline ABRASIVE & $\# 600 \mathrm{SiC}$ & $\# 600 \mathrm{SiC}$ & $\# 600 \mathrm{SiC}$ & $\# 600 \mathrm{SiC}$ & $\# 600 \mathrm{Sic}$ \\
\hline SLURRY MIX (Ib/gal). & 2 & 2 & 2 & 2 & 2 \\
\hline SLURRY OIL & PC & $P C$ & $P C$ & $P C$ & $P C$ \\
\hline EFFICIENCY (TYP) & -- & .54 & 1.03 & .99 & .95 \\
\hline WEAR RATIO & --- & .085 & .077 & .050 & .041 \\
\hline KERF WIDTH & --- & .0119 & .0112 & .0119 & .0106 \\
\hline PRESSURE $\left(0 \mathrm{z} / \mathrm{in}^{2}\right)$ & --- & 683 & 182 & 124 & 90 \\
\hline THICKNESS (AVE.) & --- & .02109 & .02185 & .02107 & .02242 \\
\hline STD. DEVIATION . : & --- & .00084 & .00116 & .00053 & .00119 \\
\hline TOTAL VARIATION (AVE) & --- & .00108 & .00088 & .00134 & .00151 \\
\hline STD. DEVIATION & --- & .00086 & .00057 & .00062 & .00089 \\
\hline STD. DEVIATION (AVE.) & -- & .00056 & .00046 & .00070 & .00079 \\
\hline STD. DEVIATION & --- & .00042 & .00029 & .00031 & .00046 \\
\hline VARIATION (AVE.WAFER) & --- & .00057 & .00038 & .00083 & .00044 \\
\hline
\end{tabular}


TABLE 1

SUMMARY OF SLURRY SAWING - PARAMETER STUDY

\begin{tabular}{|c|c|c|c|c|c|}
\hline PARAMETER & $1-031$ & $1-032$ & $1-033$ & $1-034$ & $1-041$ \\
\hline DATE & $4 / 12-73 / 76$ & $4 / 21 / 76$ & $4 / 15-16 / 76$ & $4 / 20-21 / 76$ & $5 / 13-14 / 7$ \\
\hline MATERIAL & $\operatorname{Si}\{111\}$ & $\operatorname{Si}\{111\}$ & $\operatorname{Si}\{111\}$ & Si $\{111\}$ & $\operatorname{Si}\{111\}$ \\
\hline LOAD (oz/blade) & 4 & 2 & 4 & 4 & 4 \\
\hline SLIDING SPEED (in/min) & 1600 & 1600 & 1600 & 1600 & $480-1920$ \\
\hline BLADE SIZE (inch) & $.008 \times 1 / 2$ & $.004 \times 3 / 16$ & $.006 \times 1 / 2$ & $.006 \times 1 / 4$ & $.008 \times 11$ \\
\hline SPACER (inch) & .025 & .025 & .025 & .025 & .025 \\
\hline KERF LENGTH & .984 & .984 & .984 & .984 & .984 \\
\hline ABRASIVE & $\# 600 \mathrm{SiC}$ & $\# 600 \mathrm{SiC}$ & $\# 600 \mathrm{SiC}$ & $\# 600 \mathrm{SiC}$ & $\# 600 \mathrm{Si}$ \\
\hline SLURRY MIX (lb/gal) & 2 & 2 & 2 & 2 & 2 \\
\hline SLURRY OIL & PC & PC & $\mathrm{PC}$ & PC & $\mathrm{PC}$ \\
\hline EFFICIENCY (TYP) & .97 & 1.04 & .95 & .91 & .90 \\
\hline WEAR RATIO & .070 & .056 & .065 & .070 & .049 \\
\hline KERF WIDTH & .0123 & .0086 & .0107 & .0099 & -- \\
\hline PRESSURE $\left(0 z / i n^{2}\right)$ & 331 & 237 & 380 & 409 & 339 \\
\hline THICKNESS (AVE.) & .02071 & .02044 & .02031 & .02107 & -- \\
\hline STD. DEVIATION & .00087 & .00172 & .00201 & .00136 & -- \\
\hline TOTAL VARIATION (AVE) & .00134 & .00226 & .00137 & .00167 & --- \\
\hline STD. DEVIATION & .00095 & .00174 & .00113 & .00087 & --- \\
\hline STD. DEVIATION (AVE.) & .00075 & .00120 & .00070 & .00086 & --- \\
\hline STD. DEVIATION & .00049 & .00060 & .00057 & .00042 & --- \\
\hline VARIATION (AVE.WAFER) & .00101 & .00153 & .00069 & .00072 & -- \\
\hline
\end{tabular}


TABLE 1

SUMMARY OF SLURRY SAWING - PARAMETER STUDY

\begin{tabular}{|c|c|c|c|c|c|}
\hline PARAMETER & $1-042$ & $1-051$ & $1-052$ & $1-053$ & $1-054$ \\
\hline DATE & $5 / 20-21 / 76$ & $5 / 17-18 / 76$ & $5 / 19-20 / 76$ & $5 / 26-27 / 76$ & $6 / 17-18 / 76$ \\
\hline MATERIAL & Sif117\} & $\operatorname{Si}\{100\}$ & $\operatorname{Si}\{100\}$ & Si $\{100\}$ & $\operatorname{Si}\{100\}$ \\
\hline LOAD (oz/blade) & 4 & 4 & 4 & 6 & 4 \\
\hline SLIDING SPEED (in/min) & 1600 & 1600 & 1600 & 1600 & 1300 \\
\hline BLADE SIZE (inch) & $.008 \times 1 / 4$ & $.008 \times 1 / 4$ & $.008 \times 1 / 4$ & $.008 \times 1 / 4$ & $.008 \times 1 / 4$ \\
\hline SPACER (inch) & .025 & .025 & .025 & .016 & .016 \\
\hline KERF LENGTH & .984 & .984 & 1.968 & 2.75 & 1.968 \\
\hline ABRASIVE & $\# 600 \mathrm{SiC}$ & $\# 600 \mathrm{SiC}$ & $\# 600 \mathrm{SiC}$ & $\# 600 \mathrm{SiC}$ & $\# 600 \mathrm{SiC}$ \\
\hline SLURRY MIX (lb/gal) & $1 / 2$ & 2 & 2 & 2 & 2 \\
\hline SLURRY OIL & $\mathrm{PC}$ & $\mathrm{PC}$ & $P C$ & PC & $\mathrm{PC}$ \\
\hline EFFICIENCY (TYP) & .82 & .95 & .81 & .80 & .91 \\
\hline WEAR RATIO & .069 & .067 & .079 & -- & .074 \\
\hline KERF WIDTH - & .0120 & .0124 & .0107 & .0109 & .0109 \\
\hline PRESSURE $\left(\mathrm{oz} / \mathrm{in}^{2}\right)$ & 339 & 329 & 189 & 201 & 186 \\
\hline THICKNESS (AVE.) & .02101 & .02064 & .02227 & .01372 & .01309 \\
\hline STD. DEVIATION & .00177 & .00097 & .00044 & .00053 & .00102 \\
\hline TOTAL VARIATION (AVE) & $.00 i 8 i$ & .00170 & .00062 & .00175 & .00071 \\
\hline STD. DEVIATION & .00140 & .00075 & .00036 & .00086 & .00052 \\
\hline STD. DEVIATION (AVE.) & .00092 & .00088 & .00033 & .00066 & .00037 \\
\hline STD. DEVIATION & .00070 & .00037 & .00019 & .00037 & .00025 \\
\hline VARIATION (AVE.WAFER) & .00111 & .00132 & .00027 & .00097 & .00030 \\
\hline
\end{tabular}


TABLE . 1 :

SUMMARY OF SLURRÝ SAWING - PARAMETER STUDY

\begin{tabular}{|c|c|c|c|}
\hline PARAMETER & $1-061$ & $1-062$ & $1-063$ \\
\hline DATE & $6 / 7-4 / 76$ & $6 / 9-11 / 76$ & $6 / 14-16 / 76$ \\
\hline MATERIAL & $\operatorname{Si}\{171\}$ & $\operatorname{Si}\{111\}$ & $\operatorname{Si}\{111\}$ \\
\hline LOAD (Oz/biade) & 3 & 3 & 3 \\
\hline SLIDING SPEED (in/min) & 1250 & 1300 & 1300 \\
\hline BLADE SIZE (inch) & $.008 \times 1 / 4$ & $.008 \times 1 / 4$ & $.008 \times 1 / 4$ \\
\hline SPACER (inch) & .025 & .025 & .025 \\
\hline KERF LENGTH & .984 & .984 & .984 \\
\hline ABRASIVE & \#1200 SiC & $\# 1000 \mathrm{SiC}$ & $\# 800 \mathrm{SiC}$ \\
\hline SLURRY MIX (1b/gal) & $1 / 8-1$ & $2-3$ & $1-2$ \\
\hline SLURRY OIL & Varied & Varied & PC \\
\hline . & & & \\
\hline EFFICIENCY (TYP) & .332 & .52 & .79 \\
\hline WEAR RATIO & .110 & .749 & .100 \\
\hline KERF WIDTH & .0097 & .0097 & .0105 \\
\hline PRESSURE $\left(o z / \mathrm{in}^{2}\right)$ & 314 & 313 & 291 \\
\hline THICKNESS (AVE.) & .02329 & .02326 & .02254 \\
\hline STD. DEVIATION & .00027 & .00055 & .00107 \\
\hline TOTAL VARIATION (AVE) & .00115 & .00737 & .00071 \\
\hline STD. DEVIATION & .00059 & .00086 & .00043 \\
\hline STD. DEVIATION (AVE.) & .00061 & .00058 & .00036 \\
\hline STD. DEVIATION & .00031 & .00036 & .00021 \\
\hline VARIATION (AVE.WAFER) & .00080 & .00053 & .00036 \\
\hline
\end{tabular}




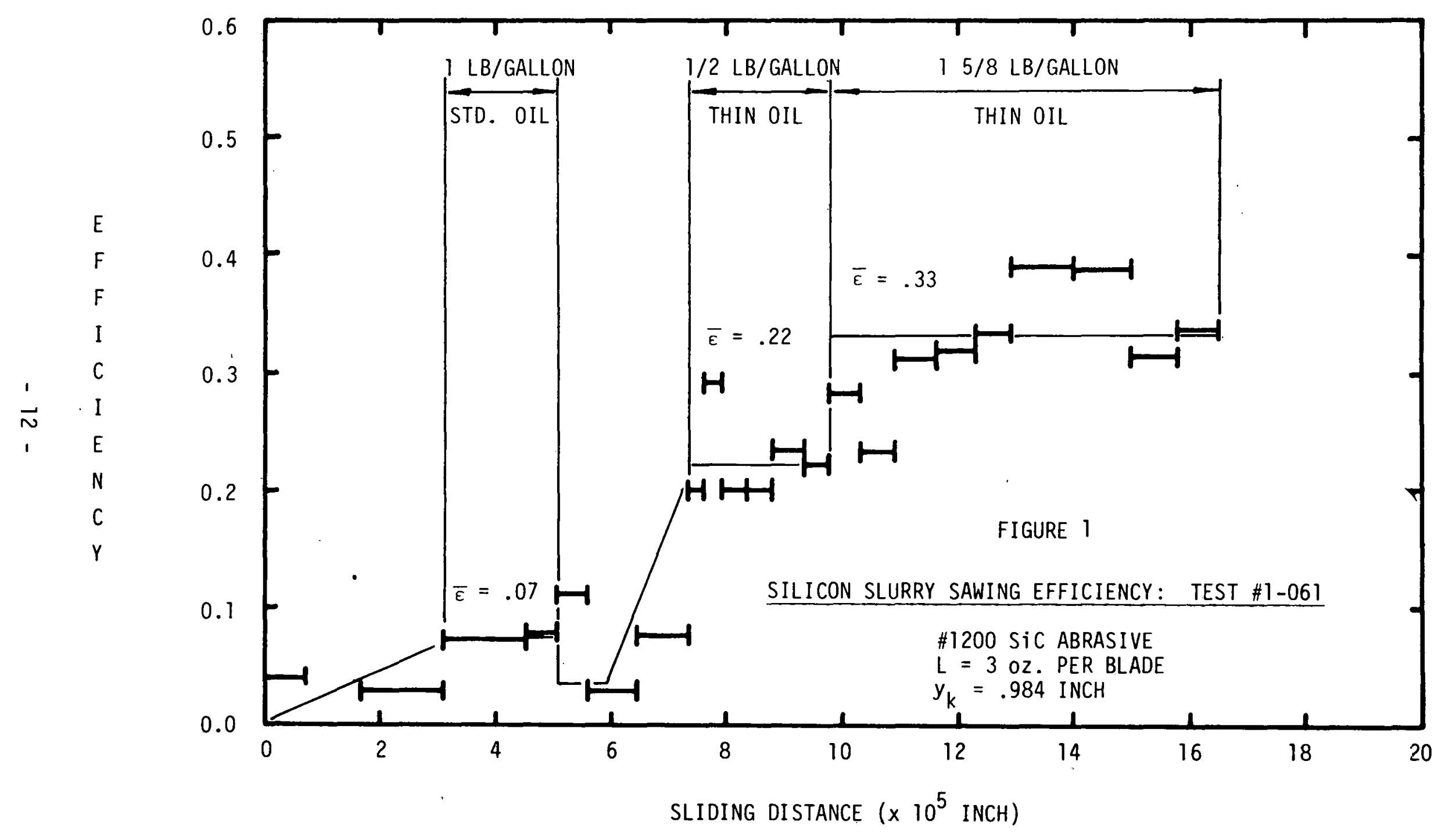




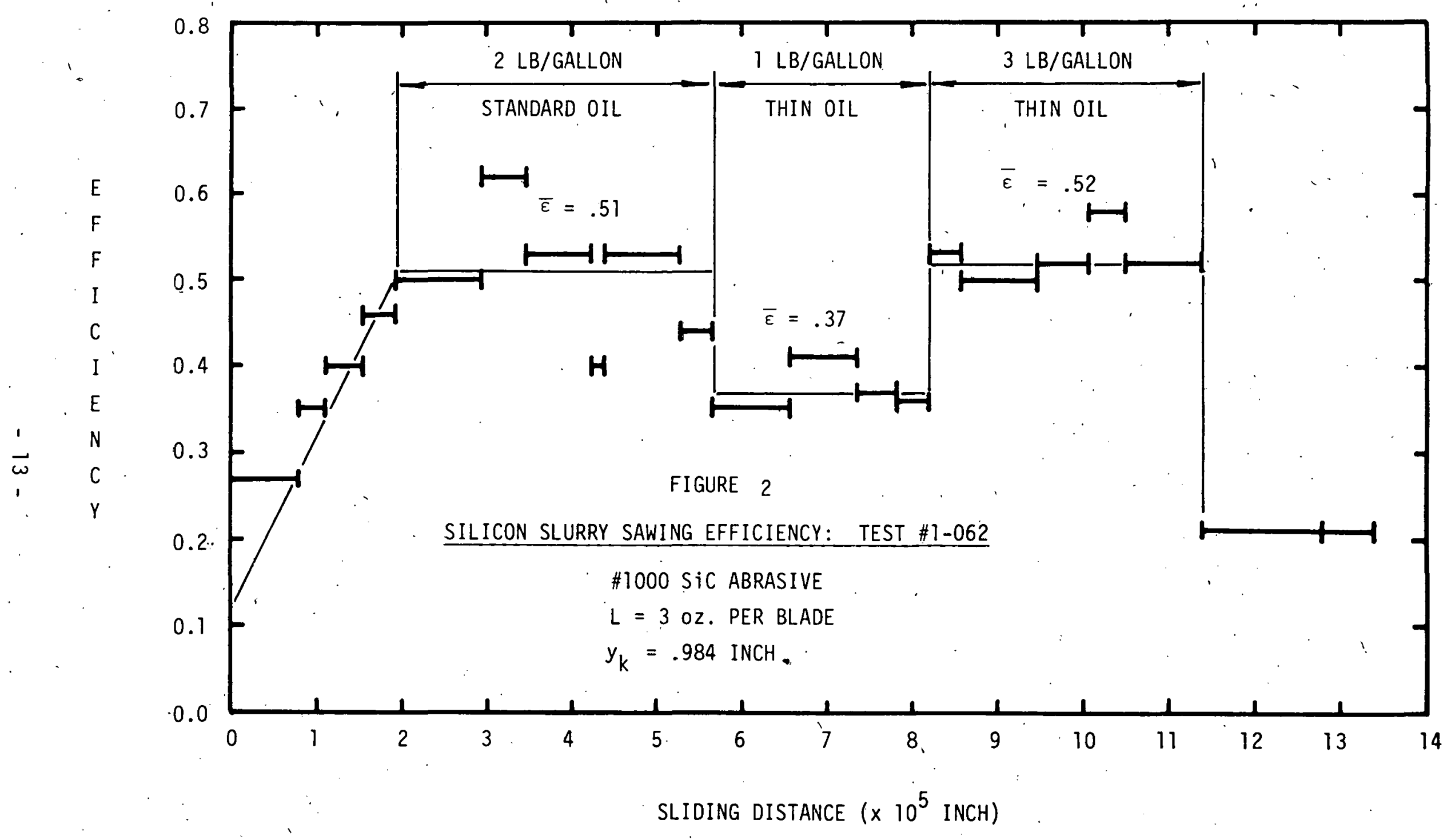




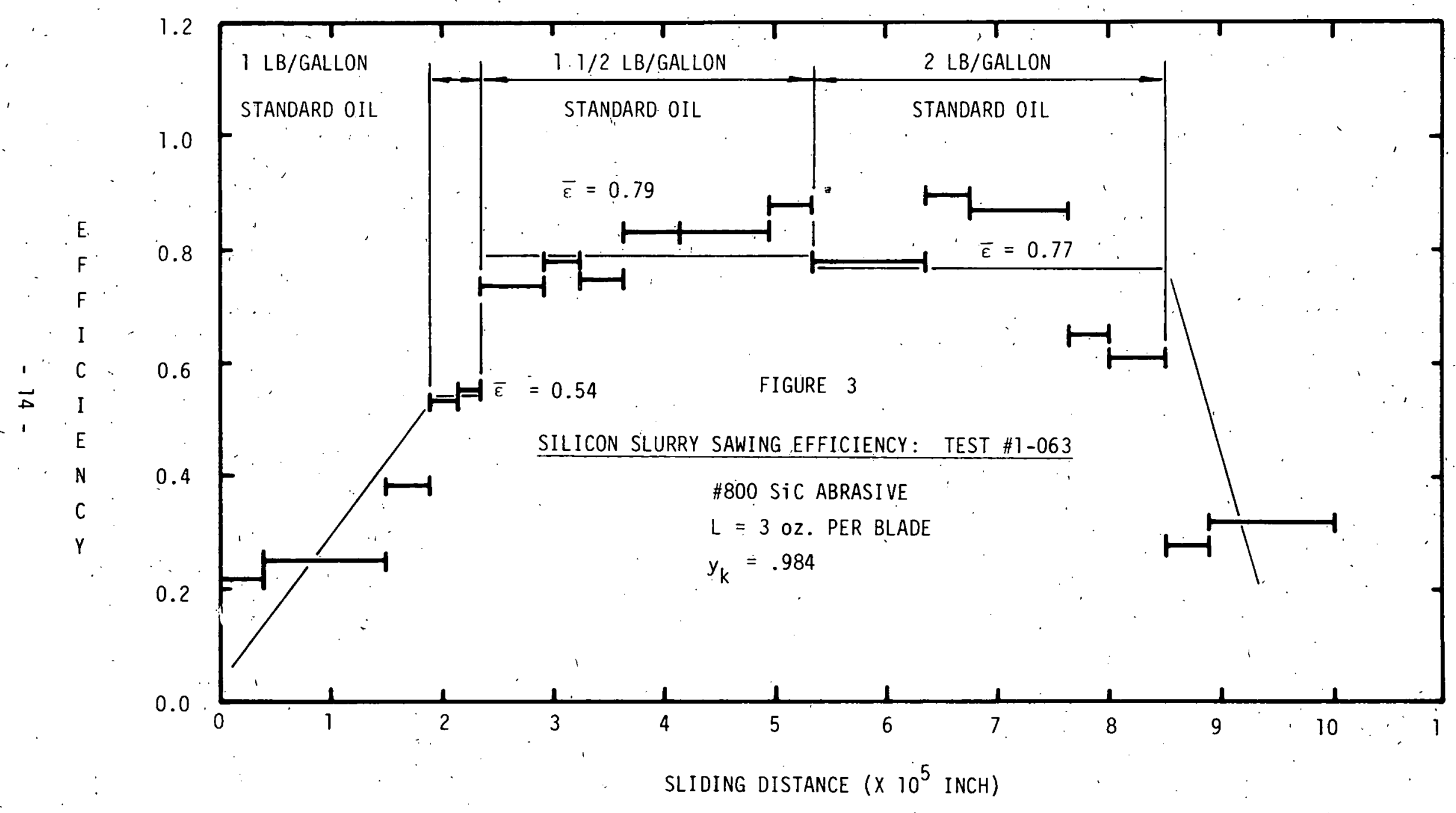




\subsection{TECHNICAL DISCUSSION}

\subsection{Cutting Efficiency}

The concept of cutting efficiency was developed in the First Quarterly Report to predict cutting rate of a slurry sawing system given varying conditions of work material size (kerf length, $x_{k}$ ), work hardness, $p$, blade and abrasive size (as related to kerf width, $\left.x_{k}\right)$, bladehead speed, $d \ell / d t$. The efficiency, $\bar{\varepsilon}$, can be viewed as a relative measure of the performance of the individual abrasive particles on a blade. The efficiency should reach a maximum when all particles are capable of removing work material in an unobstructed fashion. If a degree of abrasive rolling exists, little cutting can occur and efficiency of the system will be low. On the contrary, if too few abrasive particles are present on a blade, the cutting load will be carried by sliding contact between the blade and the work. This condition will also be marked by low cutting efficieñcy and, consequently, low cutting rate.

Figure 4 shows a plot of cutting efficiency vs. the cutting pressure for all tests from Table 1 with the standard slurry mixture of \#600 SiC abrasive. It is obvious that the unit of cutting efficiency is an accurate measure of the cutting capability of a slurry sawing system. As the pressure on a blade is reduced, the cutting efficiency increases slightly. As a function of load of kerf alone, the efficiency does not follow as specific a trend. This indicates that, for a specific condition of abrasive particles on a blade, the load carried by an individual abrasive particle will determine the efficiency of cutting.

If higher loads, narrower kerf width and finer abrasives are to be used to improve the wafering process of silicon, the introduction and consistency of slurry will be all important in: maintaining high cutting rates (cutting effićiency). A high cutting efficiency will be used to judge the proper performance of any cutting system attempted. 


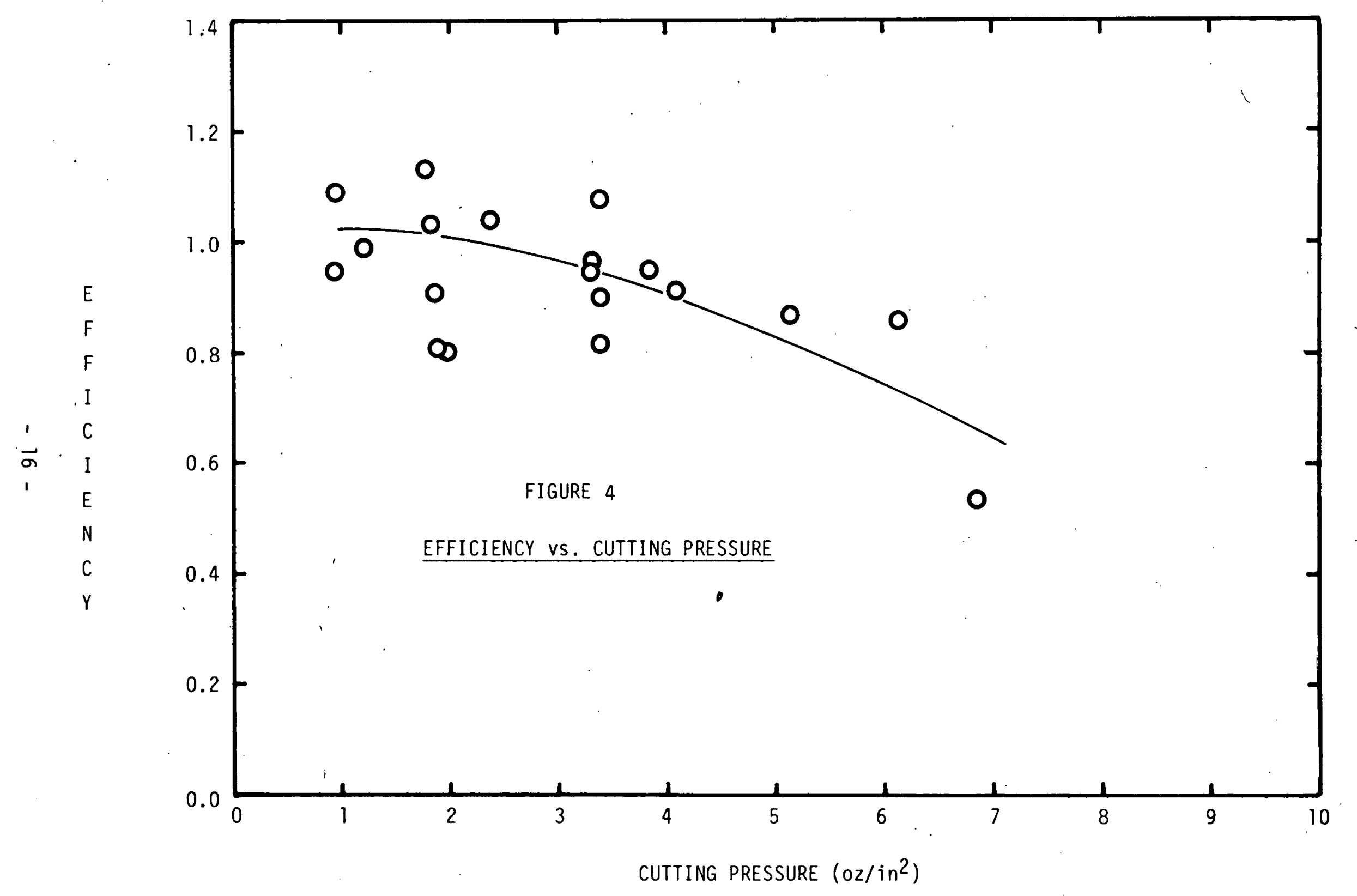




\subsection{Blade Wear}

The wear of blades will occur in a loose abrasive slicing system. Particles must be free to enter and leave the area of cutting in order to continually replenish cutting edges. This condition prevents limited cutting lifetime experienced by fixed abrasive blades (see Appendix - Multiblade Slicing of Hard Materials with Fixed Abrasive Blades). With the relatively free motion of abrasive particles, some particles will not imbed in the blades, and will roll in the cutting interface. This rolling component does not reduce cutting rate since so few particles may be involved, but it may be reasonably assumed to be the major contributor to wear of the blades.

A section of blade can be assumed to wear away in proportion to its removal of work material. This may be assumed to also be proportional to its sliding distance across the work piece. The ends of a blade do not pass completely across the work and thus wear less than the central portion of a blade, which completely passes through the work on each stroke of the bladehead. In common applications of slurry sawing, the wear of blades occurs with removal of the lower cutting edge only. There is little or no wear associated with the sides of blades. The profile of the worn portion of a blade, assuming that wear is related to relative sliding distance, is given by

$h(y)=h_{0}$

$$
\left(|y|<\frac{\ell_{s}-y_{k}}{2}\right)
$$

$$
=h_{0} \quad\left(1-\frac{|y|-\frac{\ell_{s}-y_{k}}{2}}{y_{k}}\right)\left(\frac{\ell_{s}-y_{k}}{2} \leq|y| \leq \frac{\ell_{s}+y_{k}}{2}\right)
$$

$\ell_{s}$ is the bladehead stroke, $y_{k}$ is the material kerf length, $y$ is the distance from the center of the blade, and $h(y)$ is the height 
of the blade remoyed by wear. The total volume of blade worn away, $V_{b l a d e}$, can be related to the worn height at the center of the blade, $h_{0}$.

$$
v_{\text {blade }}=h_{0} e_{s} t_{b}
$$

Where $t_{b}$ is the blade thickness.

The total volume of work material abraded by a blade is given by the kerf width, $x_{k}$, kerf length, $y_{k}$, and the depth of cut $z_{0}$. A wear ratio, $r$, can be used to measure the relative wear of blade material to work material, by volume

$$
r=\frac{h_{0} \ell_{s} t_{b}}{x_{k} y_{k} z_{0}}
$$

The wear ratio, $r$, from Equation 4 measures the total loss of blade material throughout a work load. It is apparent that a higher proportion of blade wear occurs during the early portion of cutting. As the blades slowly pick up more abrasive to use in cutting, cutting efficiency picks up and the rolling of abrasive particles diminishes. When maximum cutting efficiency is achieved, it is also reasonable to assume that blade wear rate is at a minimum. During the blade's "conditioning" period, the blade wear is at a relatively high level.

Figure 5 shows a plot of the wear ratio, $r$, vs. the unit cutting pressure. The results are with standard application of \#600 silicon carbide abrasive. The wear of blades is relatively consistent until the cutting pressure falls below $200 \mathrm{oz} / \mathrm{in}^{2}$. For these low pressure tests, the wafer area was large compared to other tests. With these, the "conditioning" period is small compared with the total cutting time. Therefore, blade wear may be dependent oniy on blade material and slurry type, but not on variations in load and kerf length associated with relatively good cutting efficiency. 


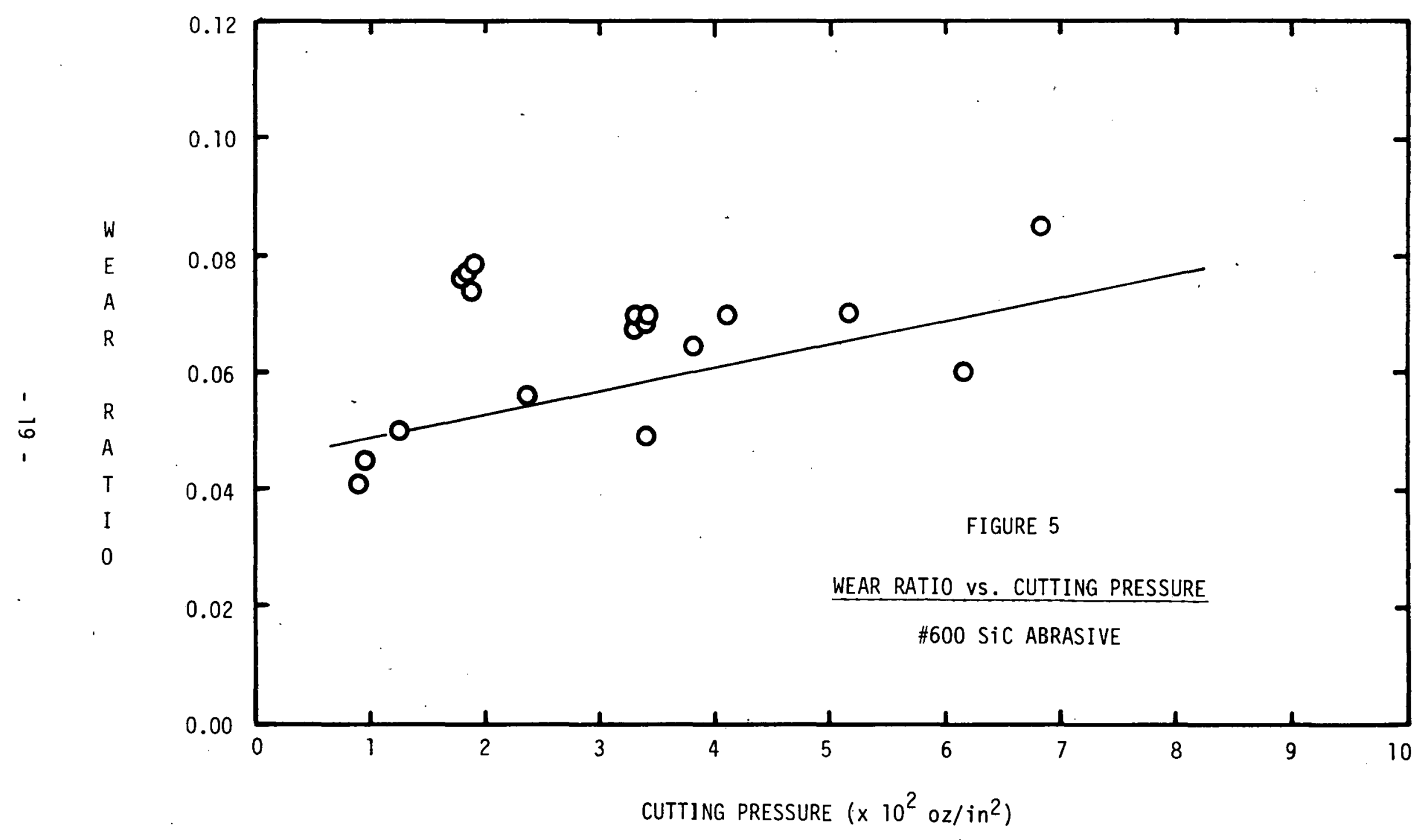




\subsection{Kerf Loss}

The kerf loss in slicing is due to the path traversed by a blade, and also by the action of abrasive to the sides of the blade. For similar cutting conditions, as shown in Figure 6 , kerf loss is linear with blade thickness. With a load of 4 ounces per blade, .984 inch kerf length, and a standard \#600 grit slurry, the kerf loss was approximately equal to the blade thickness (.004, .006 and .008 inch) plus .0042 inches.

Figure 7 shows how the abrasive kerf loss varies with cutting pressure. The abrasive kerf loss, $x_{a}$, is given the total kerf loss, $x_{k}$, less the blade thickness, $x_{b}$.

$$
x_{a}=x_{k}-x_{b}
$$

The lower blade pressures produced lower abrasive kerf loss. The effect of slurry utilization, as with efficiency, can produce excessive kerf loss. The minimum kerf loss will be sought to conserve material, and also to reduce redundant abrasive action causing lower cutting rate.

The abrasive kerf loss from different size particles can be viewed for \#600, \#800, \#1000 and \#1200 grit silicon carbide. Table 2 shows a list of the manufacturer's data for the abrasive. Abrasives have a diameter distribution for each size classification. The average and range of sizes are shown. Taking the lowest abrasive kerf loss values, the plot vs. median and maximum particle diameter are shown in Figures 8 and 9 . The abrasive kerf loss can be expected to follow a pattern like that shown in Figure 9 where the maximum particle diameter determines the kerf loss, with one particle diameter on each side of the blade. However, the limiting kerf loss is larger than the blade thickness, since the apparent width of blades is not actual thickness. Out of one to two hundred blades, not all can lie exactly parallel to the bladehead stroke. A condition somewhere between the two trends shown is closer to the actual mechanism of kerf loss. 


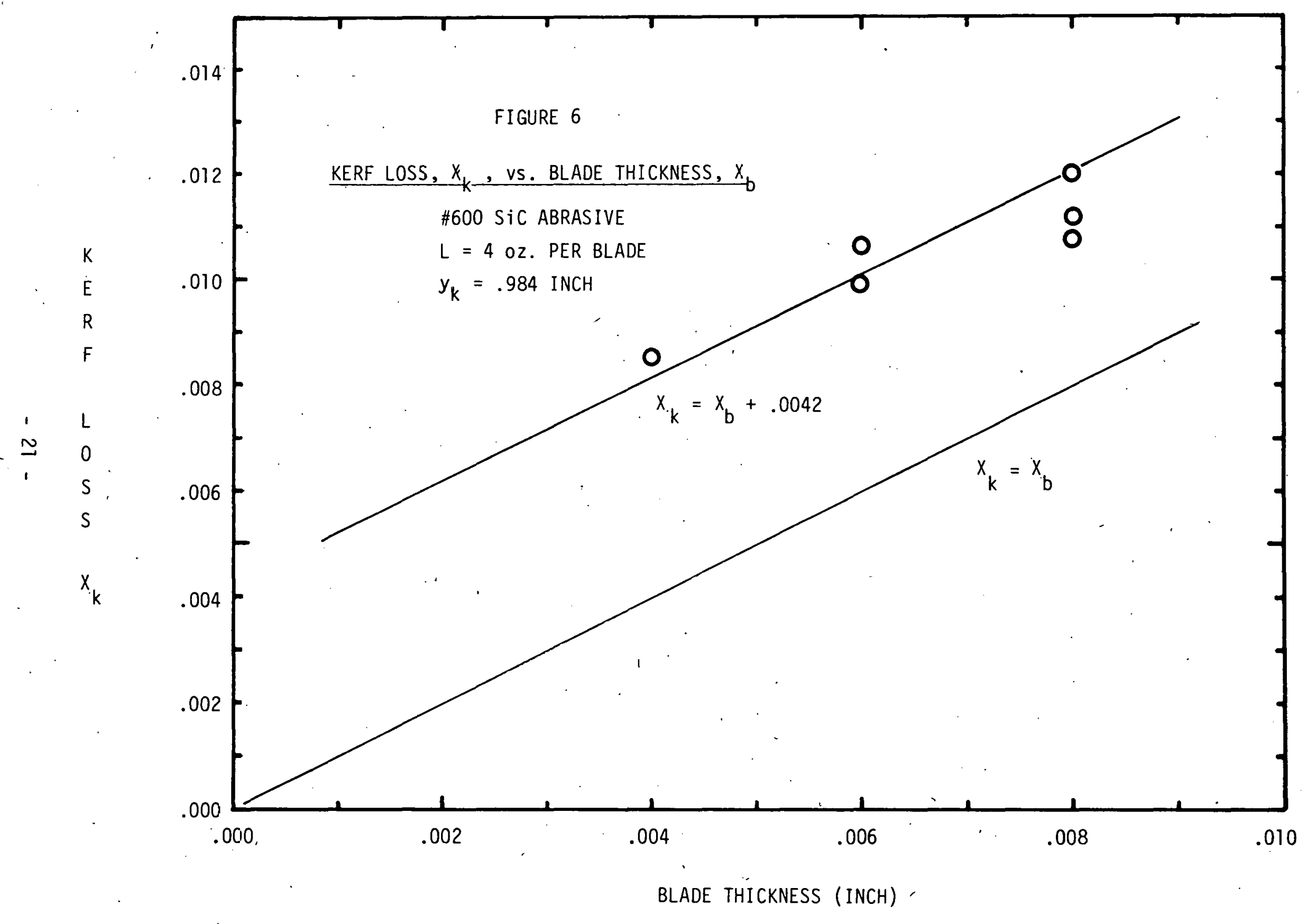




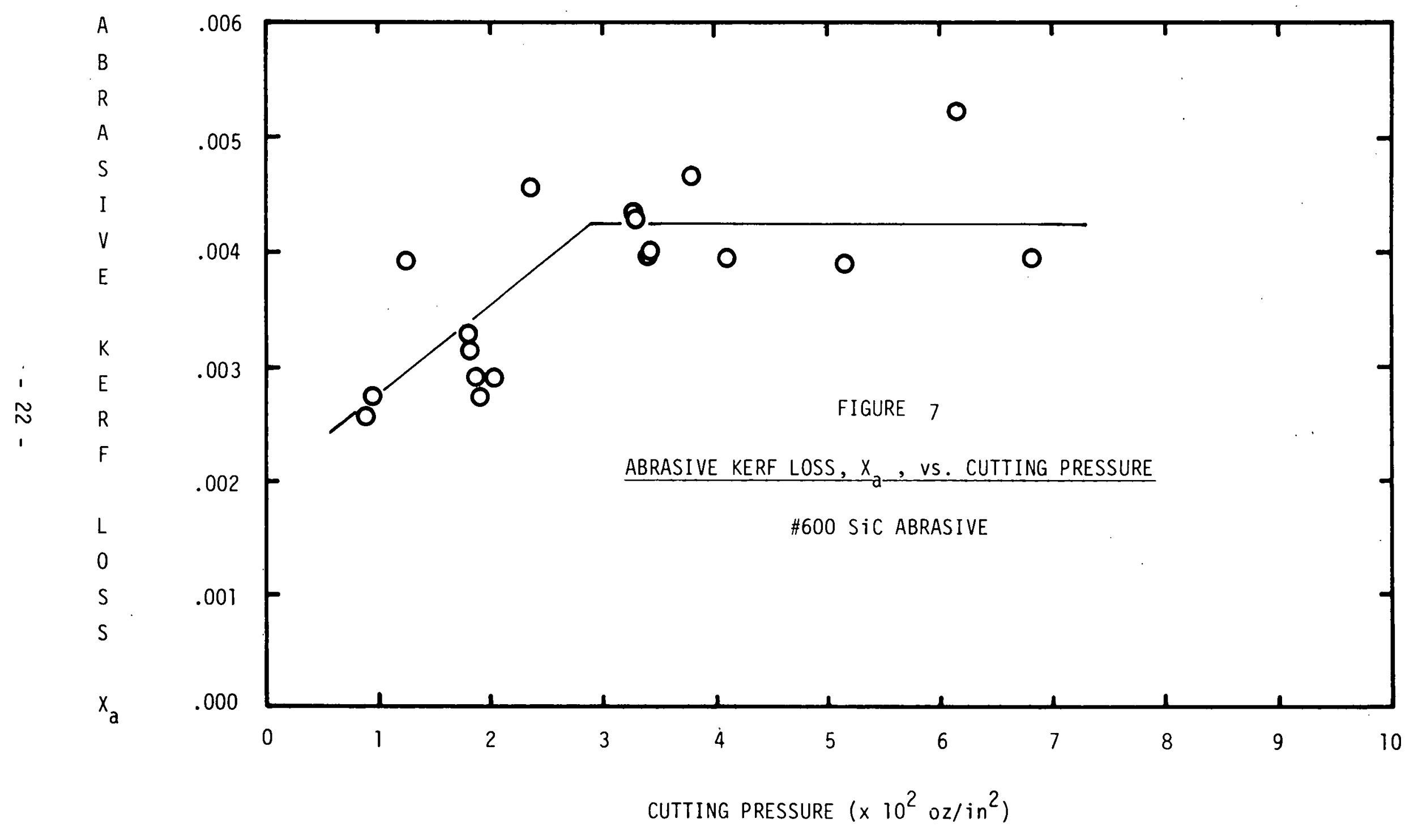


TABLE 2

AVERAGE PARTICLE SIZE OF SIC ABRASIVE

(Information from Micro Abrasives Corp.)

GRIT SIZE

400

500

600

800

1000

1200
RANGE

MICRONS

INCHES

$.00063-.00236$

$.00043-.00181$

23

16

12

10

7

$\underline{50 \% \text { SIZE }}$

INCHES

.00110

.00091

.00063

.00047

.00039

.00028 


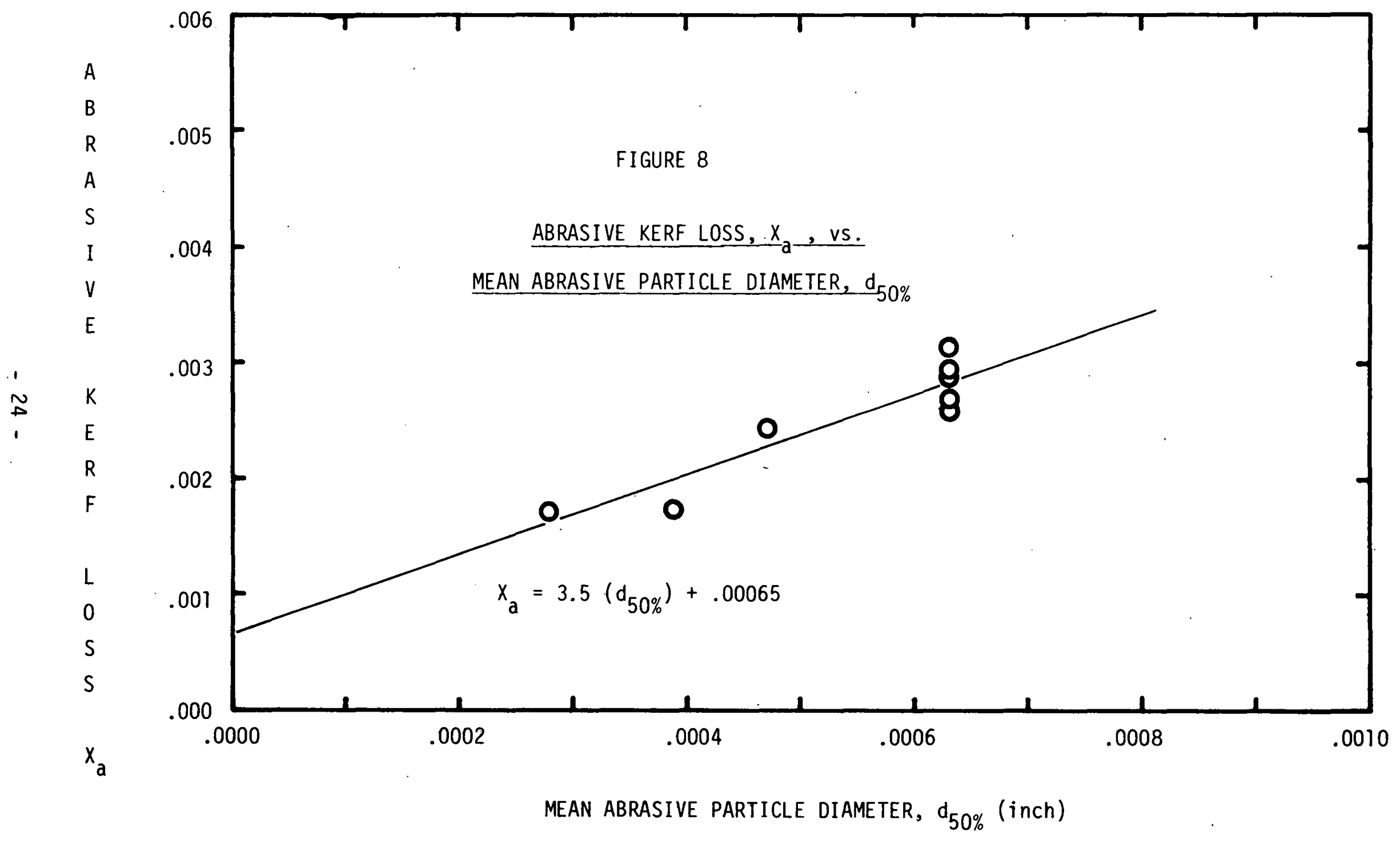




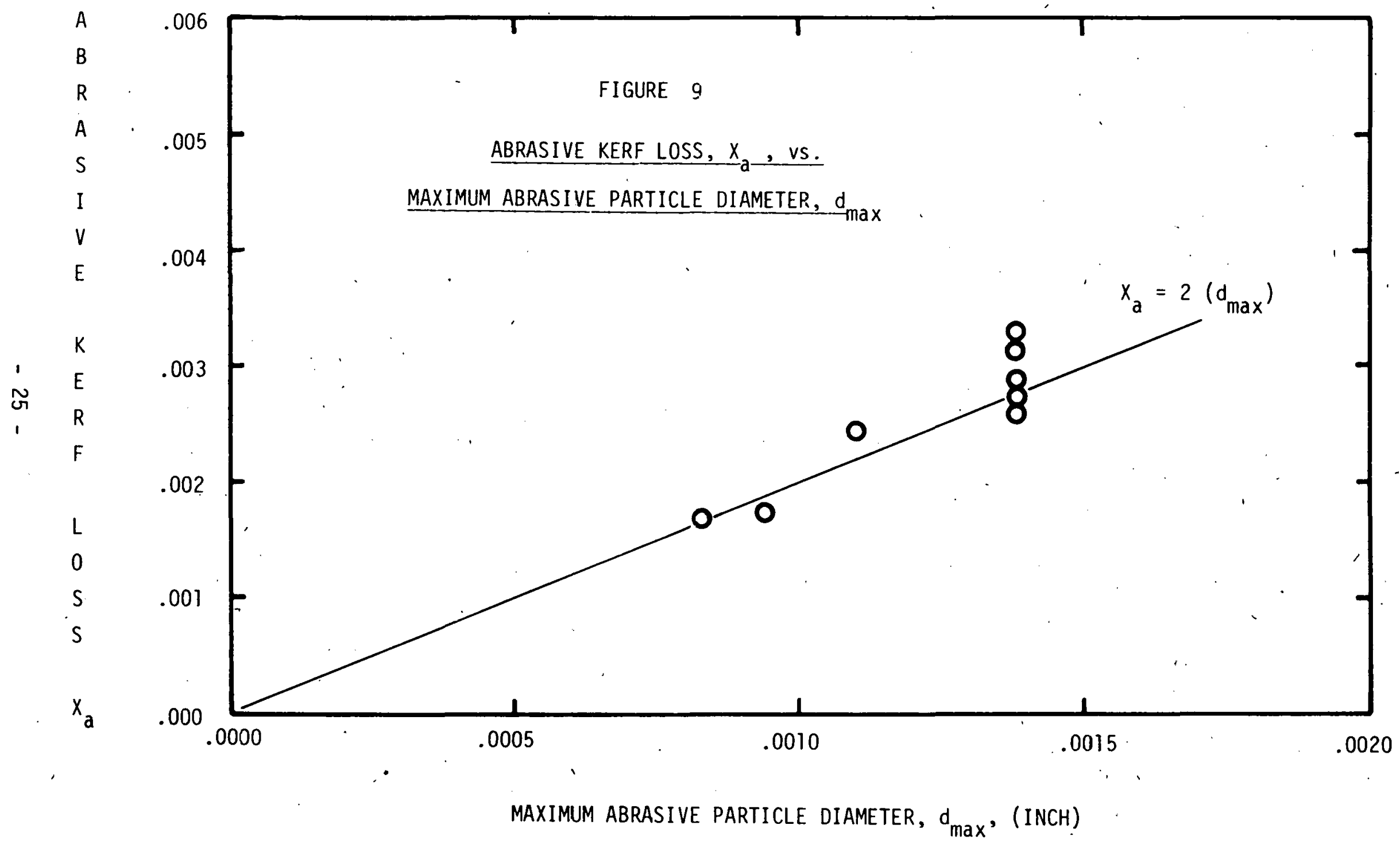




\subsection{CHARACTERIZATION DATA}

Characterization data is sumarized under the individual wafering tests in Table 1. Samples of representative silicon wafers have been delivered to JPL.

\subsection{CONCLUSIONS AND RECOMMENDATIONS}

The model for the cutting rate of abrasive slurry sawing (Equation 1) accurately shows the dependence of cutting rate on bladehead speed, cutting force, kerf length and width. The parameter of cutting efficiency is a useful measure of the relative performance of a slicing system.

Cutting efficiency, and kerf loss, improve as cutting pressure is reduced. By tailoring abrasive concentration and slurry oil, maximum cutting performance should be achieved with higher cutting pressure and with finer abrasive sizes. \#800 SiC abrasive will be used in conjunction with the development of slurry. Preliminary tests indicate relatively high cutting rate in conjunction with an abrasive kerf loss of 0.0025 inch or less. 


\subsection{FUTURE WORK}

A shift in emphasis from the original Program Plan will take place. The influence of slurry characteristics will be evaluated prior to investigating blade materials and load balancing. Plans for the next three months include:

- Completé damage and surface characterization of wafers.

- Test slurry oils for viscosity and suspension characteristics.

- Slice four inch diameter wafers less than .010 inch thick.

- Explore cutting performance with various slurries of \#800 grit abrasive.

- Order blade materials for thin blades and blade hardness variations.

- Test feedback controlled cutting force.

- Establish maximum cutting force based on wafer strength, blade stability, and shock loads. 


\title{
APPENDIX
}

\author{
New Technology
}

Man-Hours and Costs

Program Plan (Updated)

Multiblade Slicing of Hard

Materials with Fixed Abrasive

Blades 


\section{NEW TECHNOLOGY}

There was no new technology developed during the reporting period.

\section{MAN-HOURS AND COSTS}

During the reporting period of March 22, 1976 to June 20, 1976, total man-hours were 854.2 hours, and total costs were $\$ 38,330$. Previous expenditures were 479.0 hours and $\$ 11,171$. As of June 20, 1976, total program man-hours were 1333.2 and total program costs were $\$ 49,501$. 
Varian Associates

Lexington Vacuum Division JPL Contract No. 954374

Starting Date: 1/9/76

1. Background Parameter Study

1.1. Establish standardized cutting format and data collection technique

1.2. Modify saw, measure accuracy, build dynamometer

1.3. Slicing tests - effects of load, speed, slurry, work configuration on rate, wear, wafer accuracy, etc.

1.4. Wafer characterization

2. Theoretical Model

2.1. Parameterize system performance from modified abrasive wear viewpoint

\subsection{Establish practical}

limits to theory - wafer accuracy and thickness, blade instability, abrasive blunting, etc.
Program Plan

Page 1 of 5

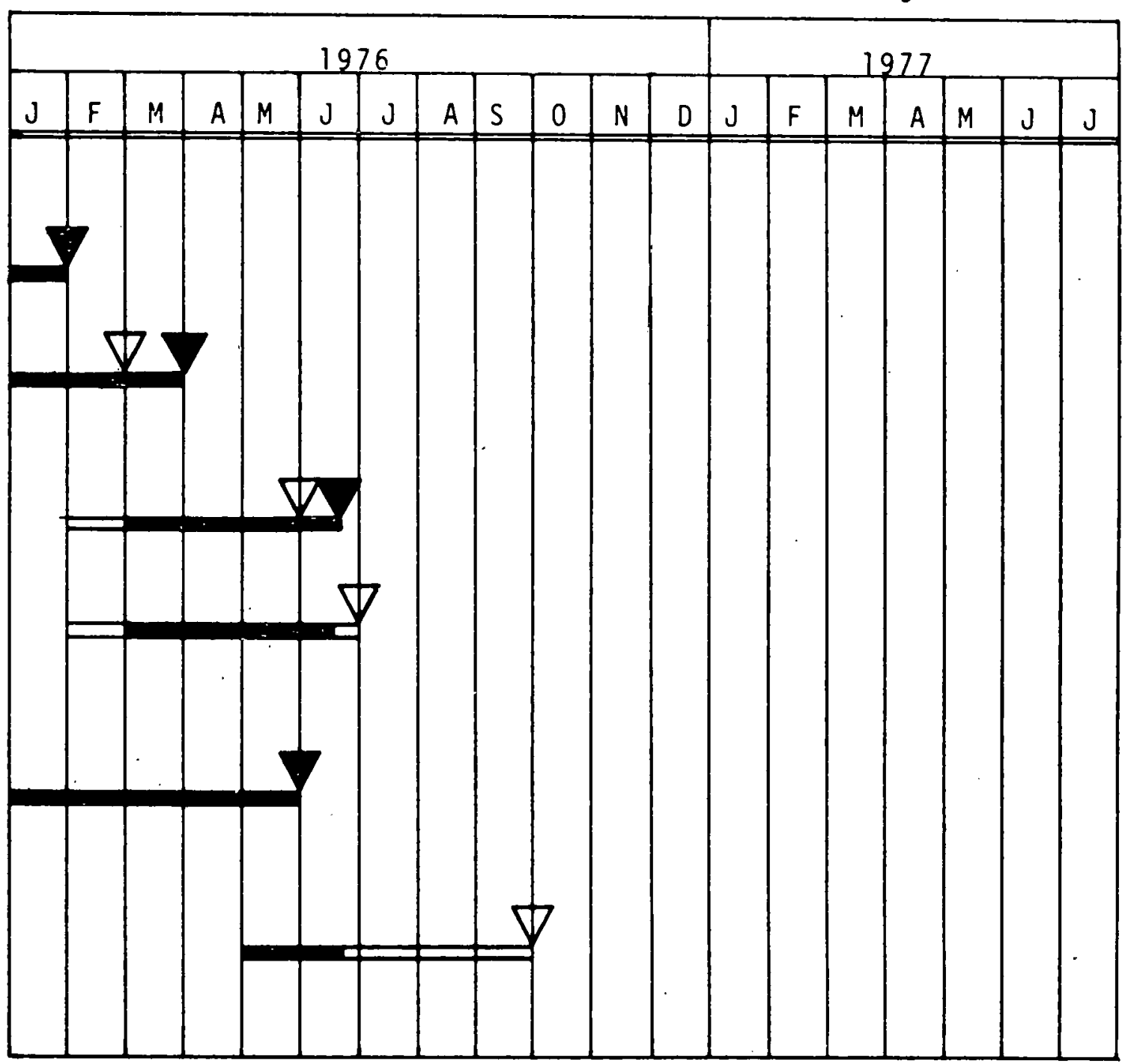

Sch 1/22/76

Updated $6 / 20 / 76$ 
3. Load Balancing

3.1. Build feedback control system - rate and force interaction

3.2. Cutting performance vs. results of 1.3 .

3.3. Wafer characterization

4. Blade Materials

4.1. Cutting tests - optimum blade material, thickness, etc. for silicon

4.2. Wafer characterization

5. Abrasives

5.1. Cutting tests - optimum size, slurry mix, application technique

5.2. Wafer characterization

6. Prototype Production Technique

6.1. Optimize previous results within guidelines of wafer specifications

6.2. Modify equipment

\begin{tabular}{|l|l|l|l|l|l|l|l|l|l|l|l|l|l|l|l|l|l|l|}
\hline \multicolumn{10}{|c|}{1976} & \multicolumn{1}{|c|}{1977} \\
\hline J & $F$ & M & A & M & J & J & A & S & O & N & D & J & F & M & A & M & J & J \\
\hline
\end{tabular}

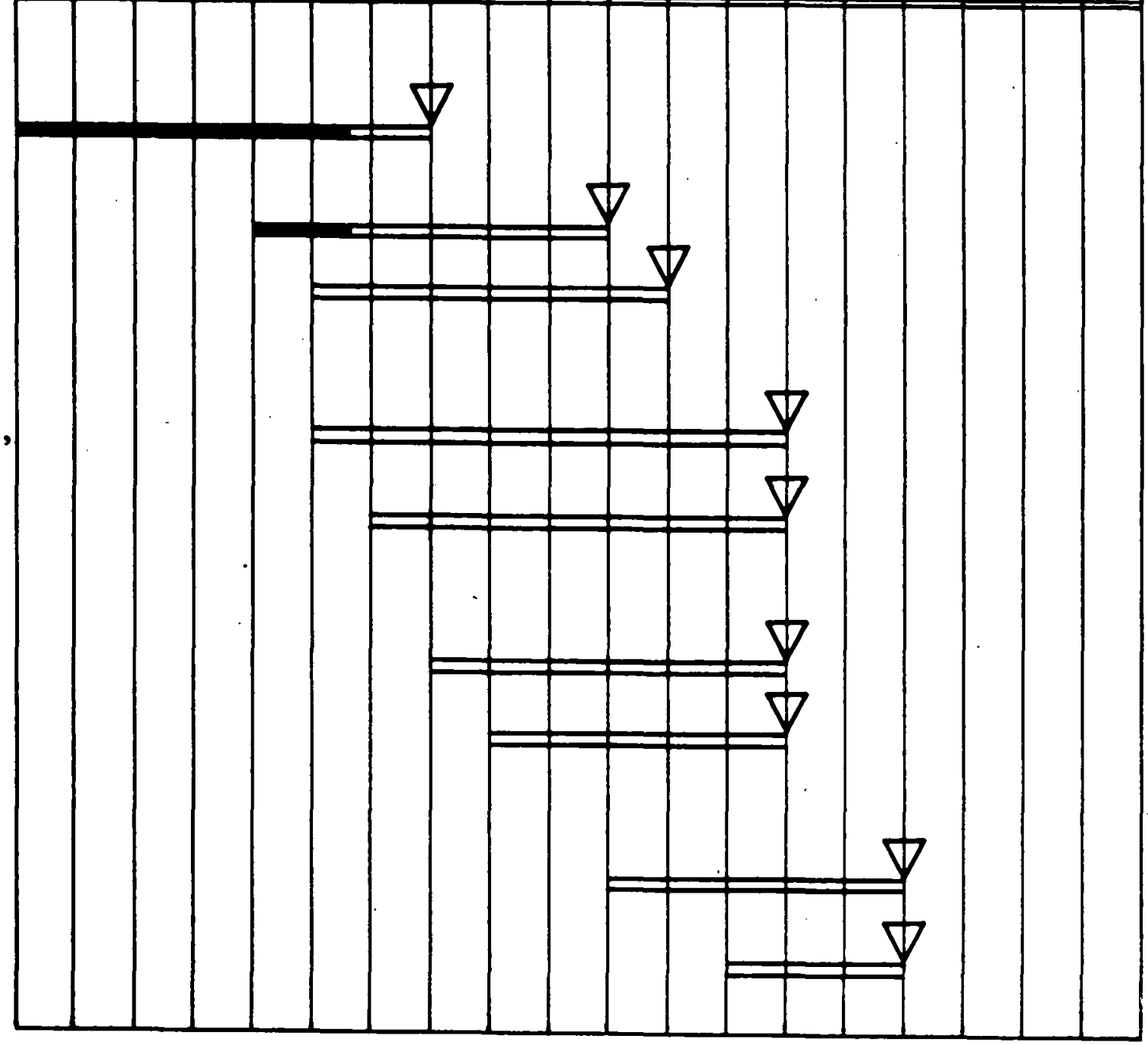

Sch $1 / 22 / 76$ Updated $6 / 20 / 76$ 
7. Evaluation

7.1. Cutting tests with final system

7.2. Economic evaluation, scale-up potential

7.3. Wafer characterization

8. Milestones

\begin{tabular}{|l|l|l|l|l|l|l|l|l|l|l|l|l|l|l|l|l|l|l|l|}
\hline \multicolumn{10}{|c|}{1976} & \multicolumn{10}{c|}{1977} \\
\hline J & F & M & A & M & J & J & A & S & O & N & D & J & F & M & A & M & J & J \\
\hline \hline
\end{tabular}

NOTE: In addition to the above Program Plan, the Lexington Vacuum Division of Varian Associates will attend the required meetings and deliver the required documentation and samples as per JPL Contract No. 954374.

$$
\begin{array}{rr}
\text { Sch } 2 / 13 / 76 \\
\text { Updated } 6 / 20 / 76
\end{array}
$$

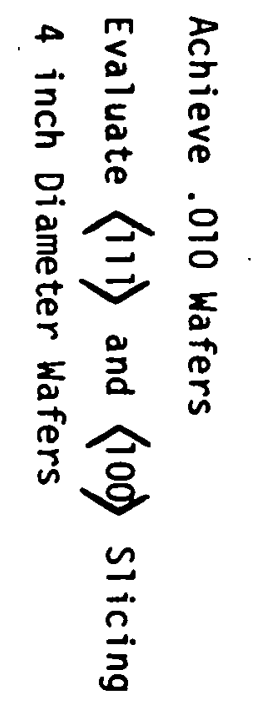

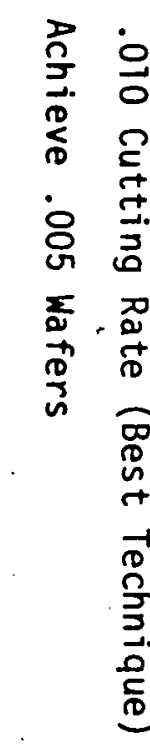

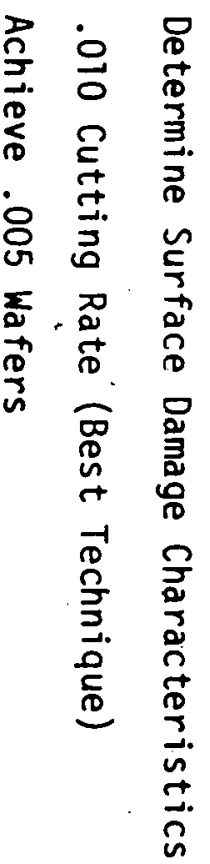

疍

党

亩

규

กัก

ลิ

号 Э.

is

苋

$\stackrel{\sigma}{<}$

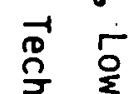

站 $\frac{5}{2}$ 
SLICING OF, SILICON INTO SHEET MATERIAL

Varian Associates

Lexington Vacuum Division

JPL Contract No. 954374

Program Plan

Starting Date: $1 / 9 / 76$

Page 4 of 5

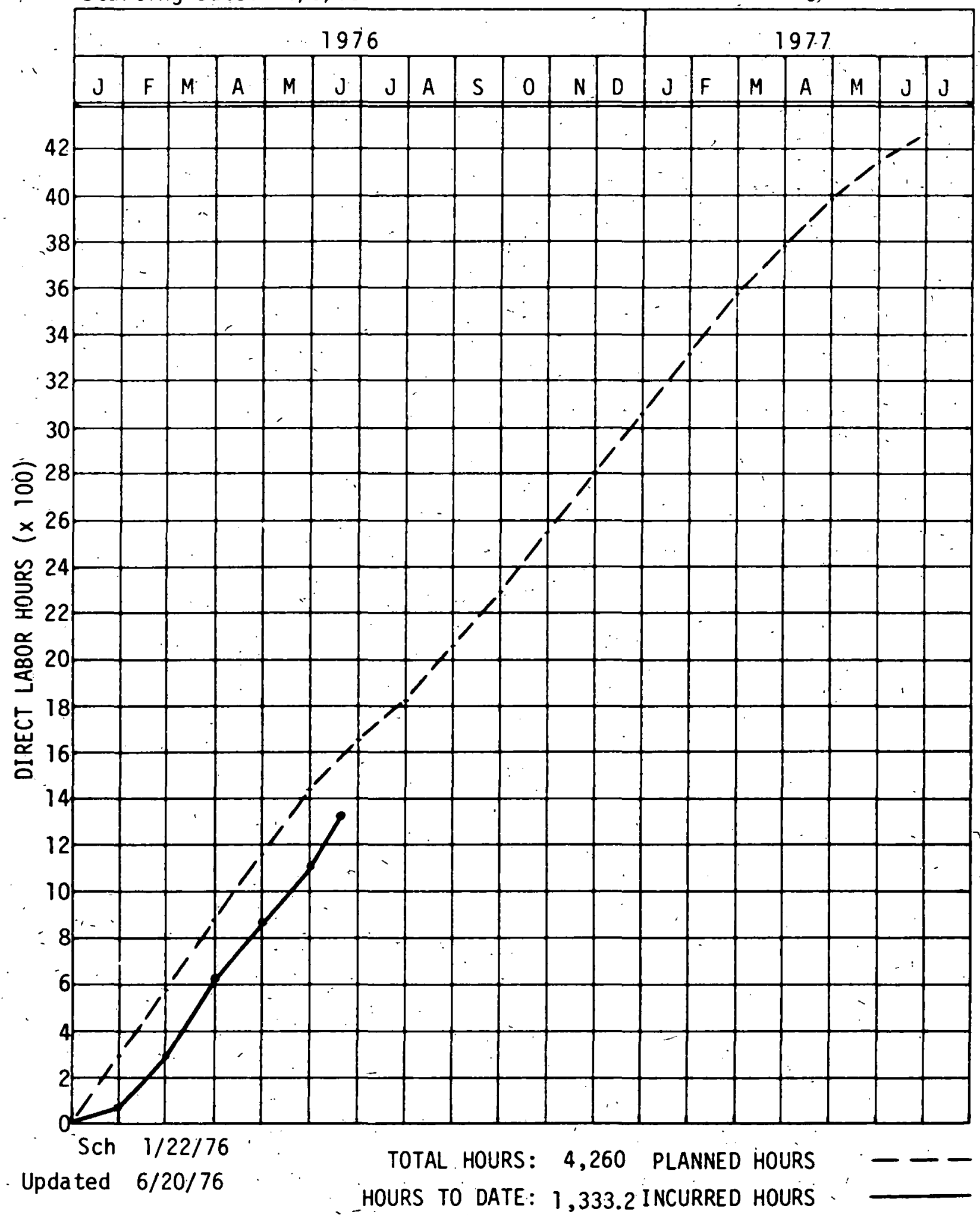


SLICING OF SILICON INTO SHEET MATERIALS

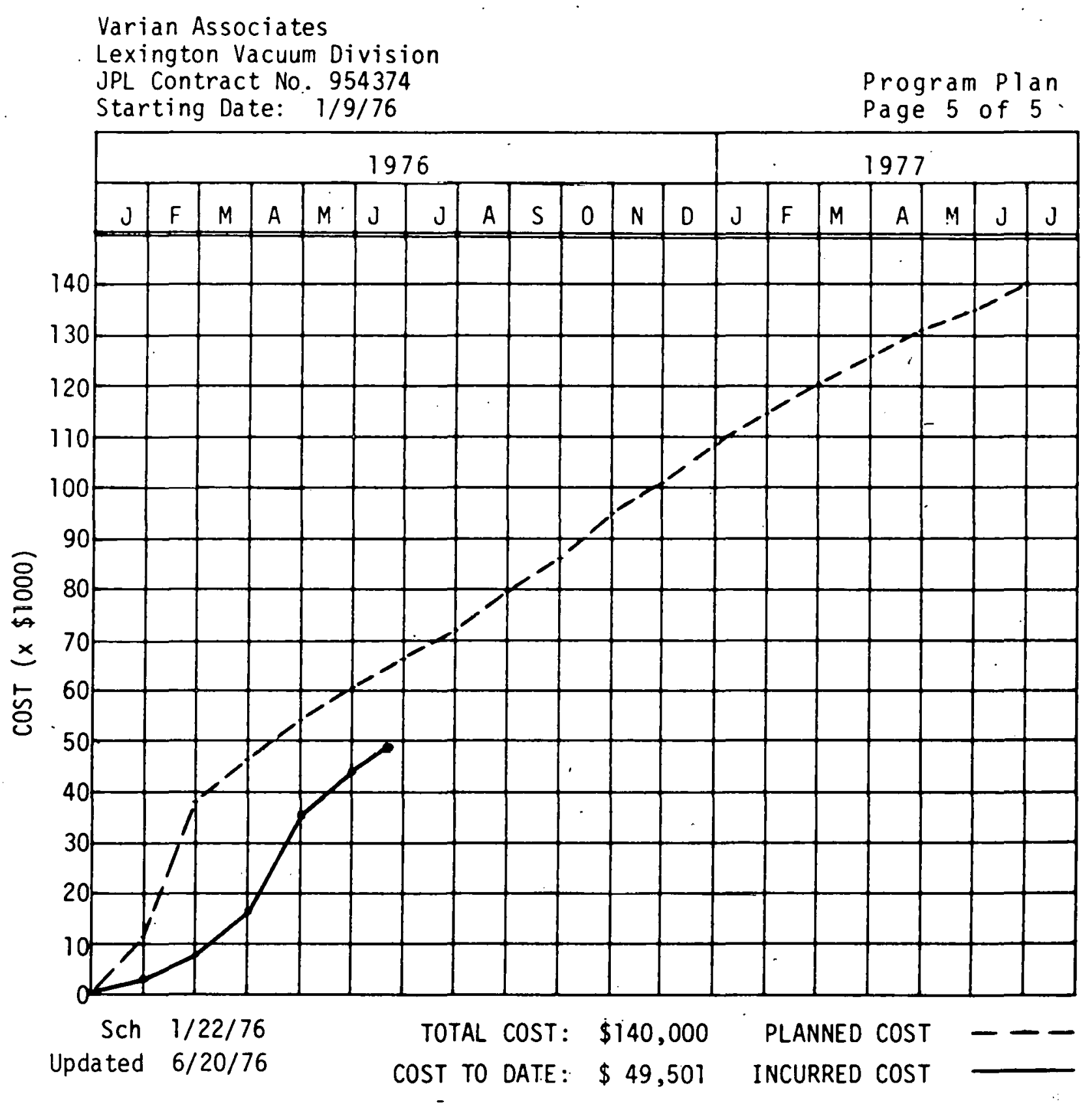


INTRODUCTION

In slicing of hard materials, one means of providing the necessary abrasion system to produce work material removal is to permanently bond abrasive particles to the cutting edges. In multiblade sawing this can provide the advantage of each blade performing in an efficient and identical fashion. The cutting points are limited in their usefulness by adhesive wear of the sharp cutting edges of the abrasive. The initial cutting rate of the system can be predicted by a slightly modified abrasive wear criterion and the useful lifetime of the blades can be described by adhesive wear of the abrasive points.

The abrasive points on a blade are driven into the work material under an applied load. The penetration of the point provides removal of work material under relative motion of the blades and work. As adhesive wear of the abrasive occurs under continuous use, a small flat spot grows on the tip of the particle. When the worn spot is of sufficient area to carry the increment of load on that particle in pure sliding, abrasive wear will cease. Throughout, the projected area of abrasive points beneath the surface will diminish and cause the cutting rate to continuously fall.

In order to maintain the cutting actions for as long as possible, the abrasive should be sufficiently hard to minimize the adhesive wear process. Also, in cutting such materials as sapphire, the only choice of abrasive is one that is harder and thus capable of penetrating the work material. Diamond is the logical choice.

\section{CUTTING RATE AND BLADE LIFE}

Consider the abrasive wear process of a single abrasive point, characterized by a half conical angle $\theta$ and carrying a small load $\Delta L$. The point indents a surface of indentation hardness, $p_{S}$, and moves through an incremental distance, $d \ell$. See Figure 1 and reference 1 and 2 for similar developments. 

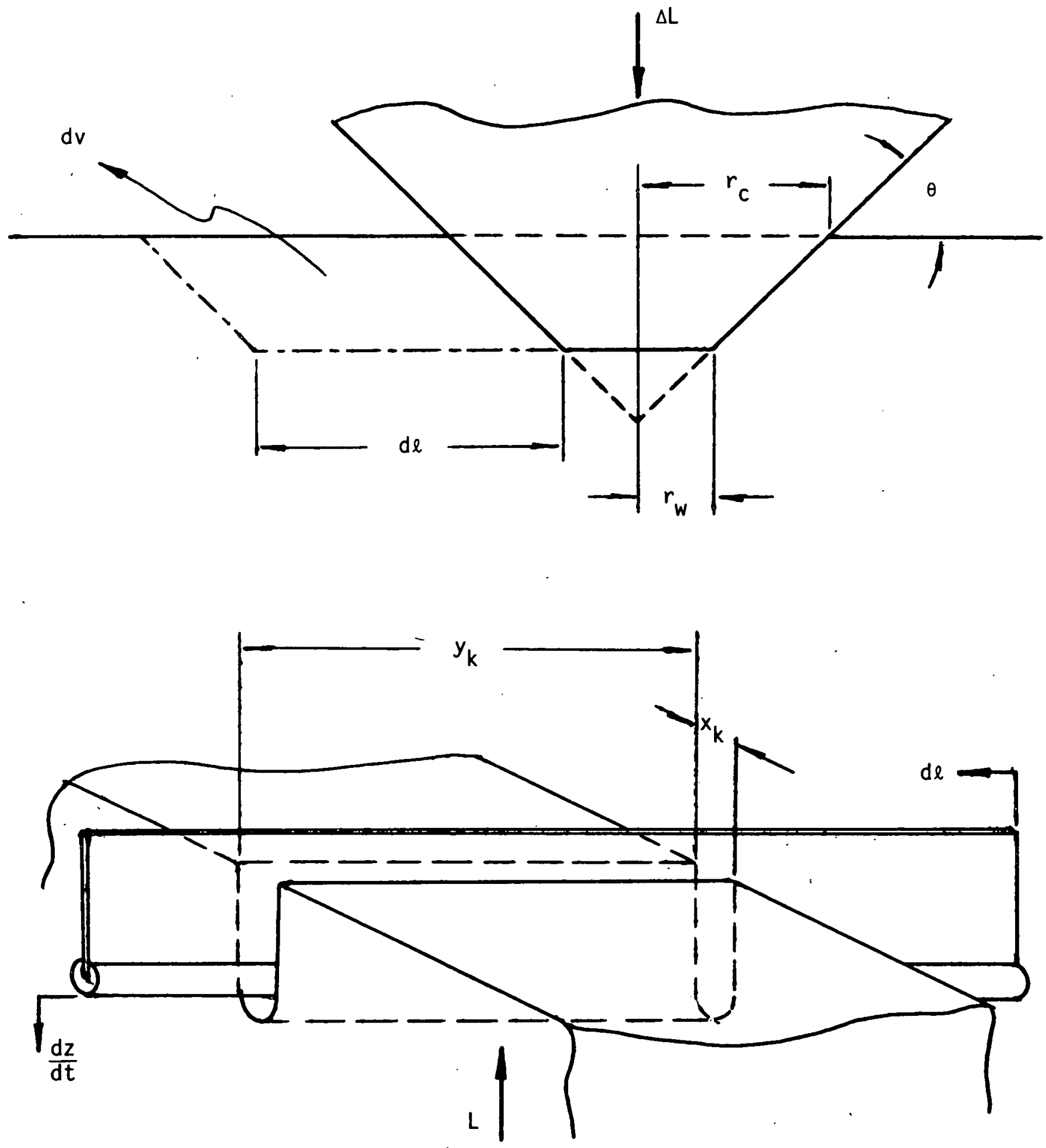

GEOMETRIES FOR MULTIBLADE SLICING WITH FIXED ABRASIVE BLADES

FIGURE 1 
The abrasive particle contacts the surface on an area, $A_{C}$

$$
A_{c}=\pi r_{c}^{2}=\frac{\Delta L}{p_{s}}
$$

If a worn spot of radius, $r_{w}$, has occurred due to the adhesive wear of the particle, the projected area beneath the surface, viewed from the sliding direction is

$$
A_{p}=r_{c}^{2} \tan \theta-r_{w}^{2} \tan \theta
$$

As the particle is moved through a distance, $d l$, the volume of work material, $d v$, swept from $i$ ts path is assumed to be

$$
d v=A_{p} \quad d \ell
$$

Substituting Equations (2) and (1) into Equation (3), volume removal rate is expressed in terms of load, work hardness, abrasive geometry and the worn spot radius.

$$
\frac{d v}{d \ell}=\frac{\Delta L \tan \theta}{\pi p_{S}}-r_{w}^{2} \tan \theta
$$

The wear volume from the point, $v_{w}$, can be assumed proportional to the amount of work material abraded by that particle, $v_{j}$,

$$
v_{w}=\frac{\pi r_{w}^{3} \tan \theta}{3}=c_{0} v_{i}
$$

Substituting Equation (5) into (4), the volume removal rate is expressed as

$$
\frac{d v}{d l}=\frac{\Delta L \tan \theta}{\pi p_{S}}-\left(\frac{3 C_{0} v_{i}}{\pi \tan \theta}\right)^{2 / 3} \tan \theta
$$

If the density of points on a blade is $n$ (points per square inch), the number of points in contact with the work at one time is

$$
N_{c}=n \quad x_{k} \quad y_{k}
$$


where $y_{k}$ is the kerf length and $x_{k}$ is the kerf width. The total volume removed per unit sliding distance, $d V / d \ell$, is

$$
\frac{d V}{d l}=N_{c} \quad \frac{d v}{d l}
$$

and the total load applied to the blade, $L$, contributes to particle loading, $\Delta \mathrm{L}$, by

$$
\Delta L=L / N_{C}
$$

The total volume of work material removed by a particle is related to the total number of particles involved in cutting. If the stroke length is $\ell_{0}$, then the total volume removed by a particle, $v_{i}$, is

$$
v_{i}=\frac{v}{n \ell_{0} x_{k}}
$$

Substituting Equations (7), (8), (9) and (10) into Equation (6) gives the expression for volume removal rate of work material per unit displacement of a blade, under conditions of worn abrasive points.

$$
\frac{d V}{d l}=\frac{L \tan \theta}{\pi p_{s}}-\left(\frac{3 c_{0} V}{\pi}\right)^{2 / 3}\left(\tan \theta n x_{k}\right)^{1 / 3} \frac{y_{k}}{\ell_{0}^{2 / 3}}
$$

It is only necessary to view two limits of this cutting rate description. When the abrasive is fresh, the cutting rate is given by the first term on the right of Equation (11).

$$
\left.\frac{d V}{d l}\right|_{t=0}=\frac{L \tan \theta}{\pi p_{S}}
$$

Since non-planar contact has not been considered (Ref. 2), $\bar{\varepsilon}$ may be substituted for $\tan \theta$ as described in the reference. To reduce Equation (12) to cutting rate, the contact area (kerf width $x$ kerf length), and reciprocating 
speed must be included

$$
\frac{d z}{d t}=\frac{d V}{d \ell} \quad\left(\frac{d \ell}{d t}\right) \quad \frac{1}{A_{0}}
$$

If the machine is characterized by a scotch yoke reciprocating mechanism with total stroke $\ell_{0}$ and operating speed $\alpha$ (RPM)

$$
\left.\frac{d z}{d t}\right|_{t=0}=\frac{L \bar{\varepsilon}}{\pi p_{s}}\left(\frac{d \ell}{d t}\right) \frac{1}{A_{0}}=\frac{L \bar{\varepsilon}}{\pi p_{s}} \frac{2 \alpha \ell_{0}}{x_{k} y_{k}}
$$

Which is identical to the cutting rate proposed for slurry abrasive sawing. The second term in Equation (11) relates to the effect of worn particles in the fixed abrasive system. Solving Equation (11) for the volume of work material worn away when zero cutting rate occurs, $d V / d \ell=0$,

$$
v_{\max }=\frac{L^{3 / 2} \tan \theta l_{0}}{p_{s}{ }^{3 / 2} y_{k}{ }^{3 / 2} n^{1 / 2} x_{k}{ }^{1 / 2} c_{0} 3 \pi^{1 / 2}} \text {. }
$$

Again, since no consideration has been given as to the non-planar abrasion constraints, a constant can be withdrawn to Equation (15) to leave only the relevant parameter weighting. The slice area cut in a sawing operation, $A_{\max }$, is given by

$$
A_{\max }=\frac{V_{\max }}{x_{k}}
$$

Substituting for $V_{\max }$, the maximum useful blade life for diamond blades is related to the contact force, $L$; blade length, $\ell_{0}$, work material hardness, $p_{s}$, kerf length, $y_{k}$, kerf width, $x_{k}$, and abrasive packing density, $n$

$$
A_{\max }=\left(\frac{L}{p_{s} y_{k} x_{k}}\right)^{3 / 2} \frac{C^{1} l_{0}}{n^{1 / 2}} .
$$


Diamond coated blades produced by Norton Company (defined "E" process) were used in a Varian Model 686 multiblade wafering machine to cut standard $1 / 4$ inch thick blocks of sapphire. The blades were .008 inch thick, $1 / 2$ inch high, 15 inch clamped length, and made of hardened 1095 steel. Diamond abrasive is bonded to the lower edge of the blades by a plating process, producing a wrap around cutting edge. Three sizes of abrasive, (\#105, \#120 and \#240 grit diamond) were used for the tests described here.

The blades are clamped in the bladehead of the multiblade wafering saw, and are elongated to $80 \%$ of the yield strain of the blade stock $(.090$ inch elongation for a 15 inch clamped length of blade). The bladehead is reciprocated by a scotch yoke assembly with the average reciprocating speed given as twice the drive plate revolving speed times the stroke of the bladehead. The blades are aligned parallel to the stroke direction by draw-over bolts on the movable clamp of the bladehead. The blades were aligned within .0002 inch of runout from the stroke direction.

The sapphire blocks were mounted to a machine tool dynamometer on a pneumatically controlled vertical feeding assembly. The calibrated output of the dynamometer was referenced to adjust the air pressure to the feed system and thus the total cutting force between the biades and work material. A supply of coolant water was applied to the cutting interface, and blocks of graphite on both sides of the sapphire provided support. to the block and cleaned debris from the blades during the cutting test.

A .001 inch reading dial indicator was mounted to follow the progress of the cut under the upward pressure of the vertical feed. Readings were taken at convenient intervals to measure the vertical rate of cutting.

\section{EXPERIMENTAL RESULTS}

Cutting tests were performed with three sizes of diamond for abrasive. With a fresh set of blades, the initial cutting rate can be compared with Equation (14). The cutting rate gradually decreases, as described by the process in Equation (11). At a low rate of cutting (typically .0002 inch 
per minute) the total depth of cut was recorded, and a higher load was applied. Cutting would continue with the worn blades until the rate became low again. This procedure was followed with two sets of \#120 grit diamond coated blades, and one set each of \#240 and \#105 grit diamond coated blades. The results of initial cutting rate (where applicable), total depth of cut, cutting force per blade, and other relevent machine operating parameters, are recorded in Table 1.

\section{INTERPRETATION}

Table 2 shows series of reductions of the information from the cutting tests of Table 1. The initial cutting rate of the four tests in Table 1 can be evaluated to give the value of $\bar{\varepsilon}$ (cutting efficiency). The sapphire was assumed to have a hardness of $2100 \mathrm{~kg} / \mathrm{mm}^{2}$, and Equation (14) was used to determine $\bar{\varepsilon}$.

Equation (14) can be rewritten in terms of blade cutting pressure $\left(\begin{array}{ll}L & x_{k} \\ y_{k}\end{array}\right)$, and machine parameters. Incorporating Equation (13) and Equation (14),

$$
\left.\frac{d z}{d \ell}\right|_{t=0}=\bar{\varepsilon}\left(\frac{1}{\pi p_{s}}\right)\left(\frac{L}{x_{k} y_{k}}\right)^{\cdot}
$$

The initial depth of cut per unit sliding distance (normalized cutting rate) can be expressed as proportional to unit cutting pressure on a blade, cutting efficiency $\bar{\varepsilon}$, and the hardness of the work material. Figure 2 is a plot of Equation (18), for the four tests in which fresh blades were used.

The maximum area of cutting for a given set of blades and load as defined in Equation (17) can be found from Tables 1 and 2. Rearranging Equation (17), for a given set of blades and work material, $n$ and $p_{s}$ are constants. The maximum area generated as a function of load is given by

$$
A_{\max }=C^{\prime} \cdot\left(\frac{L}{x_{k} y_{k}}\right)^{3 / 2}
$$


TABLE 1

SUMMARY OF CUTTING PARAMETERS \& RESULTS

\begin{tabular}{|c|c|c|c|c|c|c|c|c|c|c|}
\hline PARAMETER & 1 & 2 & 3 & 4 & $5 a$ & $5 b$ & 6 & $7 \mathrm{a}$ & $7 b$ & 8 \\
\hline ABRASIVE & $\# 120$ & $\# 120$ & $\# 120$ & $\# 120$ & $\# 240$ & $\# 240$ & $\# 105$ & $\# 105$ & $\# 105$ & $\# 105$ \\
\hline KERF WIDTH $x_{k}$ (INCH) & .024 & .024 & .024 & .024 & .019 & .019 & .031 & .031 & .031 & .031 \\
\hline KERF LENGTH $y_{k}$ (INCH) & .25 & .25 & .25 & .25 & .25 & .25 & .25 & .25 & .25 & .25 \\
\hline STROKE $\ell_{0}$ (INCH) & 7 & 7 & 7 & 6.5 & 6.5 & 6.5 & 6.5 & 6.5 & 6.5 & 6.5 \\
\hline LOAD L (OUNCE/BLADE) & 16.2 & 19.0 & 25.9 & 32.4 & 7.5 & 15.0 & 12.0 & 18.0 & 24.0 & 36.0 \\
\hline$\left.\frac{d x}{d t}\right|_{t=0}(I N C H / M I N)$ & .060 & -- & -- & .114 & .023 & -- & .020 & -- & -- & -- \\
\hline MAX DEPTH (INCH) & 1.230 & 1.630 & 2.406 & 2.702 & .243 & .624 & .408 & .675 & .791 & 2.337 \\
\hline
\end{tabular}


TABLE 2

REDUCTION OF CUTTING RESULTS

\begin{tabular}{|c|c|c|c|c|c|c|c|c|c|c|}
\hline TEST & 1 & 2 & 3 & 4 & $5 a$ & $5 b$ & 6 & $7 a$ & $7 b$ & 8 \\
\hline$A_{\max }\left(i n^{2}\right)$ & .307 & .407 & .602 & .675 & .061 & .156 & .102 & .169 & .198 & .584 \\
\hline EFFICIENCY $\bar{\varepsilon}$ & 2.48 & -- & -- & 2.54 & 1.70 & -- & 1.55 & -- & -- & -- \\
\hline$c^{\prime}\left(\times 10^{7}\right)$ & 8.25 & 8.61 & 8.00 & 6.91 & 8.84 & 7.99 & 5.85 & 5.28 & 4.02 & 6.45 \\
\hline PRESSURE $\left(\times 10^{3} 0 z . / \mathrm{in}^{2}\right)$ & 2.70 & 3.17 & 4.32 & 5.40 & 1.58 & 3.16 & 1.55 & 2.32 & 3.10 & 4.65 \\
\hline $\mathrm{dx} / \mathrm{d} \ell\left(\mathrm{x} 10^{-5}\right.$ in./in. $)$ & 4.46 & -- & -- & 9.13 & 1.79 & -- & 1.60 & -- & -- & -- \\
\hline PARTICLE DIAMETER (INCH) & .0056 & .0056 & .0056 & .0056 & .0025 & .0025 & .0065 & .0065 & .0065 & .0065 \\
\hline DENSITY $n\left(x 10^{3} \mathrm{in}^{-2}\right)$ & 6.38 & 6.38 & 6.38 & 6.38 & 32.0 & 32.0 & 4.73 & 4.73 & 4.73 & 4.73 \\
\hline OVERLAP $r$ & 2.68 & 2.90 & 3.38 & 3.51 & 4.25 & 6.02 & 1.62 & 1.98 & 2.29 & 2.81 \\
\hline
\end{tabular}




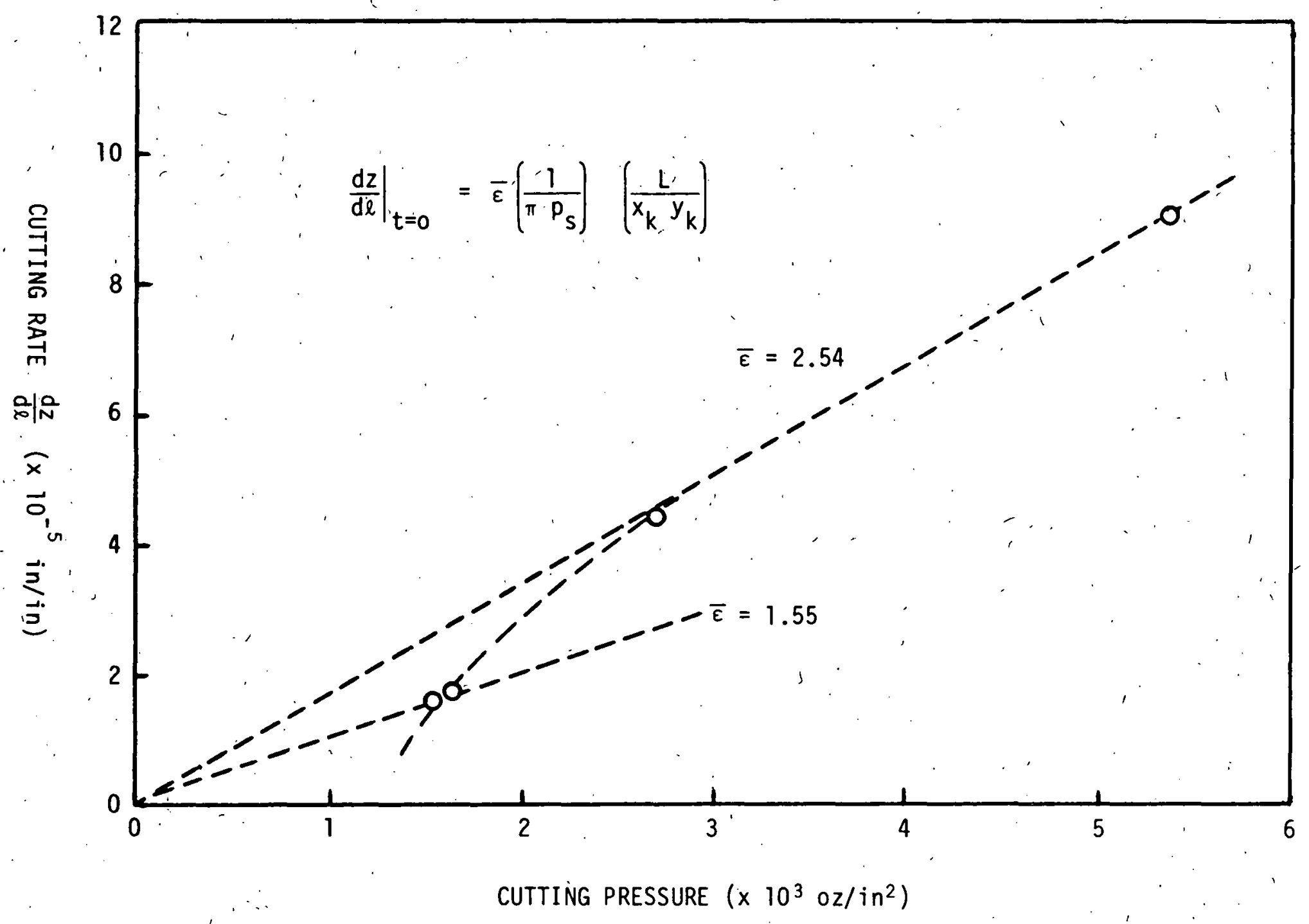

INITIAL CUTTING RATE VS. BLADE PRESSURE

FIGURE 2 
Figure 3 shows a plot of $A_{\max }$ vs. cutting pressure. The useful lifetime of a blade can be judged accurately by Equation (19).

The effect of diamond particle spacing may be considered. The process for making of diamond coated blades results in an abrasive packing density that is proportional to abrasive diameter. The point to point spacing is nearly 2.5 times the particle diameter. Consequently, the packing density of abrasive points, $n$, can be approximated as a function of particle diameter, $d_{a}$

$$
n=\frac{4}{\pi \cdot\left(2.5 d_{a}\right)^{2}}=\frac{0.20}{d_{a}^{2}}
$$

Table 2 includes a tabulation of assumed particle spacing for the three abrasive sizes used. Equation (17) can be written to show the effect of abrasive spacing alone on normalized maximum blade life.

$$
\frac{A_{\max }}{l_{0}}\left[\frac{p_{s} y_{k} x_{k}}{L}\right]^{3 / 2}=c^{\prime} / n^{1 / 2}
$$

Figure 4 shows the influence of density, $n$, on blade life. The \#105 grit blades exhibit a lower lifetime than expected with Equation (17). This is a coarse abrasive, and fewer particles contact the work material than with $\# 120$ and \#240. This could allow the improper orientation of a few abrasive particles to severely influence the overall cutting performance. Another way to view the limited lifetime is in terms of the overlap of cutting paths of individual diamonds across the width of the work material slot.

An abrasive particle produces a trough in the work material each time it passes across the surface. If the other diamonds on the blade do not overlap in their cutting sufficiently to leave a relatively flat surface, then the penetration of the abrasive on the next pass is into a rough surface. This may cause an artificially low blade life since the unworn sides of the abrasive can rest on the sides of a trough and indentation can cease with a smaller than assumed worn spot.

The overlap ratio of diamond particles can be assumed to be the average kerf width between abrasive points on a full pass of the blade 


$$
A_{\max }\left(i n^{2}\right)
$$

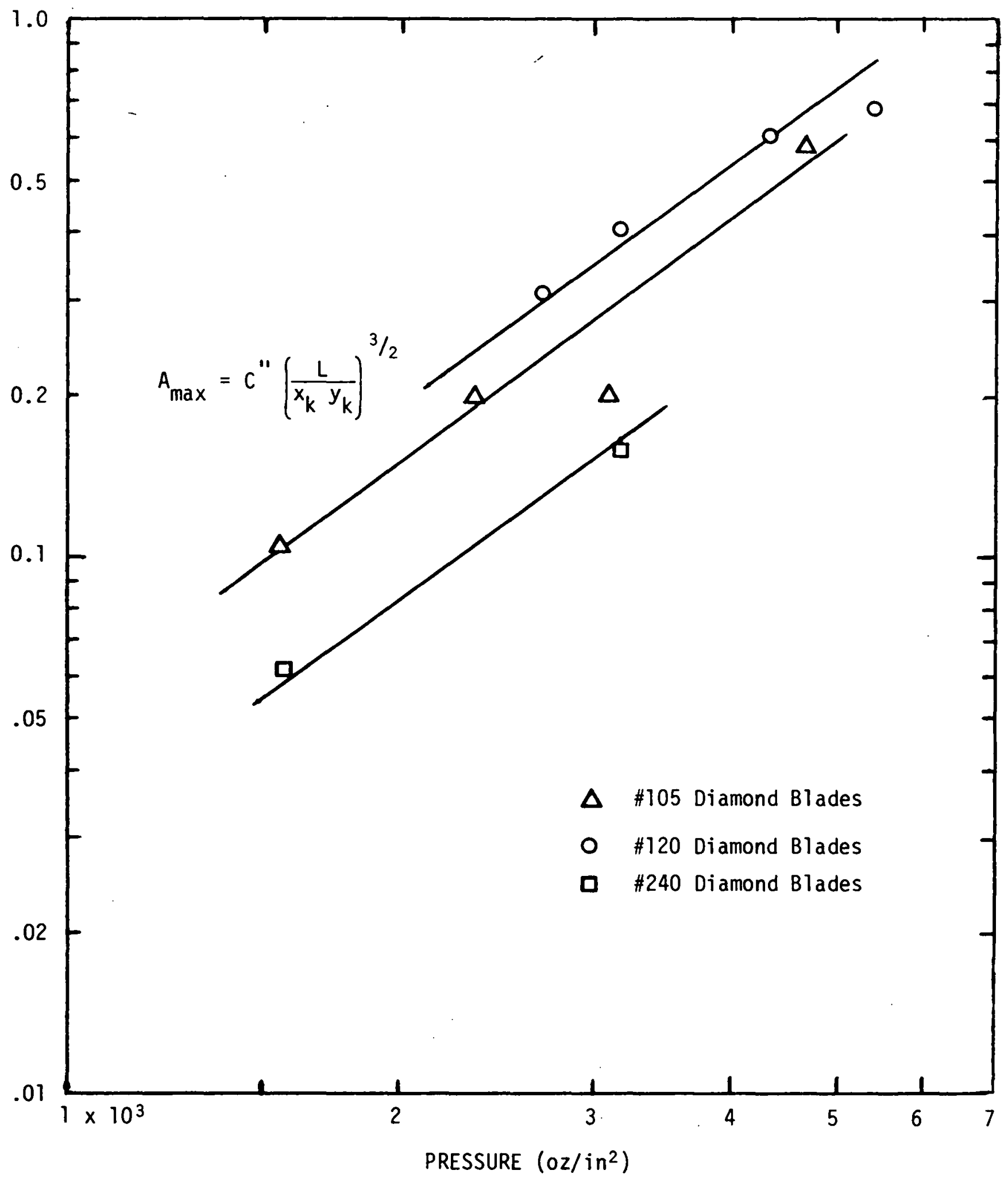

$A_{\max }$ vs. CUTTING PRESSURE FOR DIAMOND COATED BLADES

FIGURE 3 


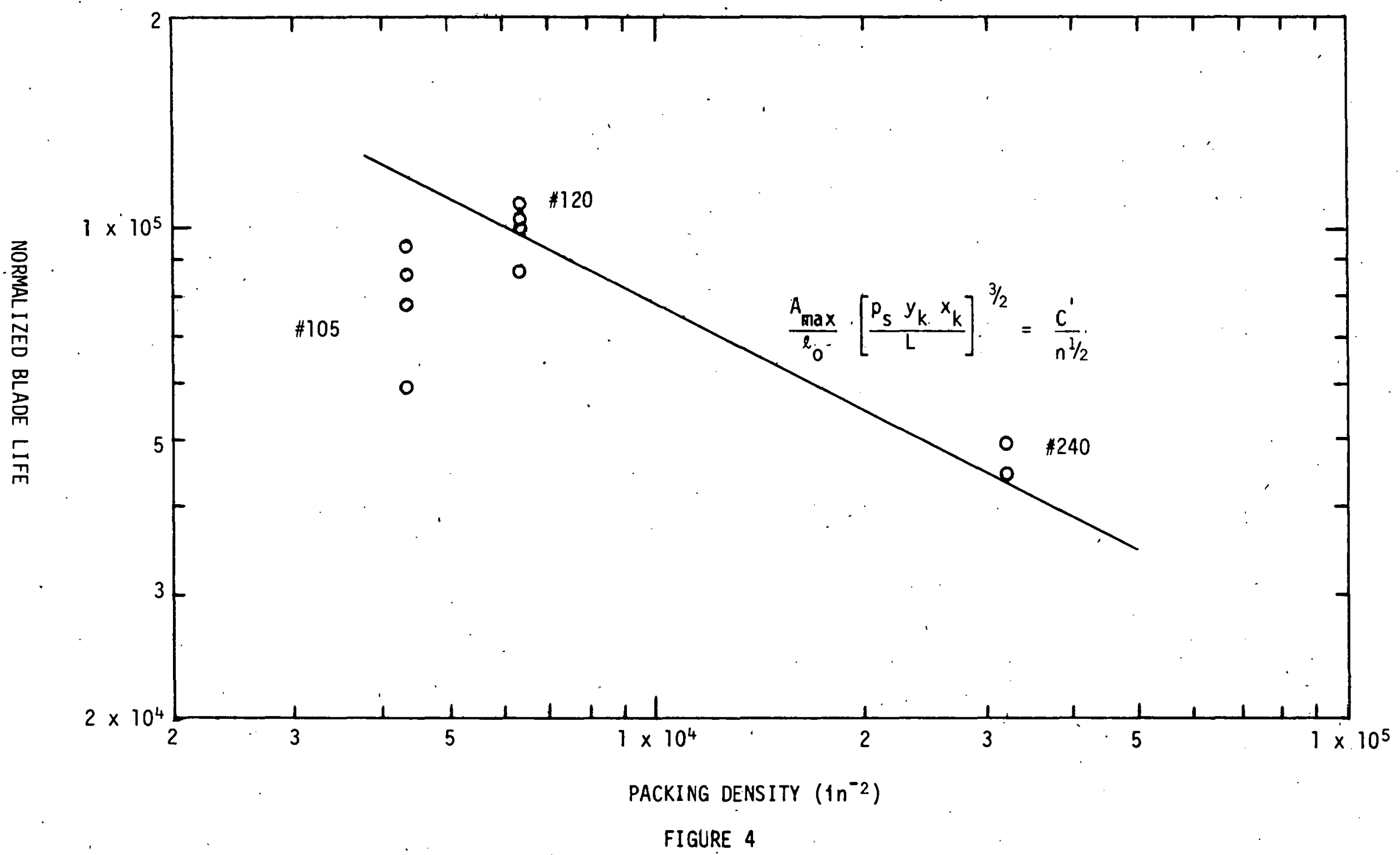

NORMALIZED BLADE LIFE VS. DIAMOND CONCENTRATION 
divided by the width of an indentation trough of a single abrasive. The width of a single trough is approximated by

$$
d_{c}=2 r_{c}=\frac{2}{\pi}\left(\frac{L}{n x_{k} y_{k} p_{s}}\right)^{1 / 2}
$$

The interspacing of troughs along the width of the blade, considering all abrasive particles on the blade stroke length, is

$$
d_{i}=\frac{1}{n \ell_{0}}
$$

The overlap ratio of interspacing of troughs to the width of a trough can be given by

$$
r=\frac{d_{c}}{d_{i}}=\frac{2 \ell_{0}}{\pi} \quad\left(\frac{L n}{x_{k} y_{k} p_{s}}\right)^{1 / 2}
$$

The overlap ratios for all tests is recorded in Table 2. The normalized blade life parameter, $C^{\prime}$, is plotted against overlap ratio in Figure 5 . It is clear that the degree of overlap is low for the \#l05 blades at the loads used. The troughing mechanism may explain the low blade life seen with \#105 diamond blades. 


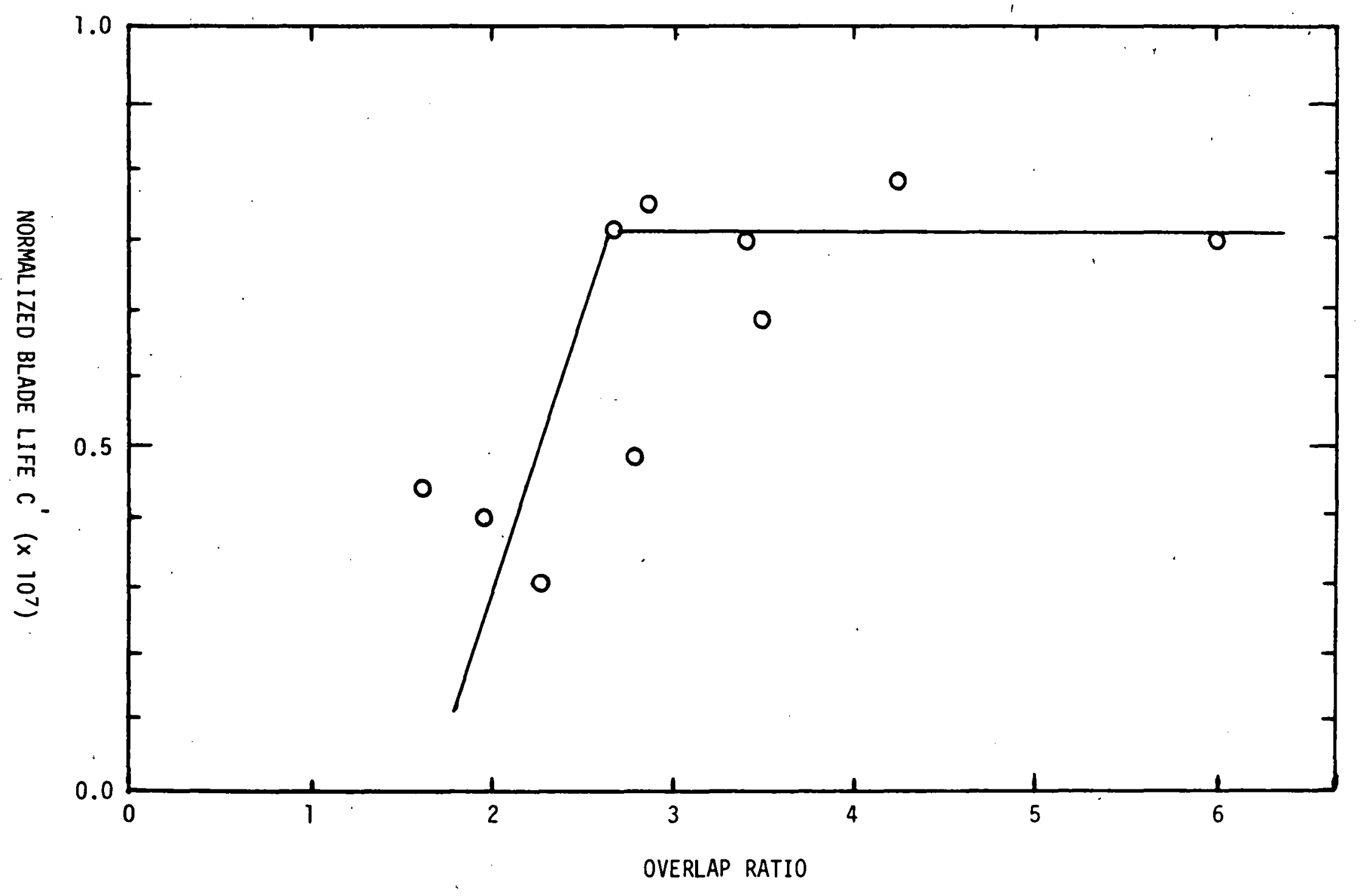

NORMALIZED BLADE LIFE $C^{\prime}$ VS. OVERLAP RATIO $r$

FIGURE 5 


\section{REFERENCES}

1. Rabinowicz, Ernest, Friction and Wear of Materials, John Wiley \& Sons, New York, 1965. pp 168-169.

2. Holden, Scott, "Slicing of Silicon into Sheet Material, First Quarterly Report", ERDA/JPL 954374 - 76/1. March 29, 1976. 